Research Article

\title{
Study of a System Dynamics Model of Wuhan Commodity Housing Price
}

\author{
Jingyi Guo $\mathbb{D}^{1},{ }^{1}$ Junwu Wang $\mathbb{D},{ }^{1}$ Denghui Liu $\mathbb{D}^{2},{ }^{2}$ Shi Qiao, ${ }^{3}$ and Han Wu $\mathbb{D}^{1}$ \\ ${ }^{1}$ School of Civil Engineering and Architecture, Wuhan University of Technology, Wuhan 430070, China \\ ${ }^{2}$ China Construction First Group Corporation Limited, Beijing 100161, China \\ ${ }^{3}$ School of Management, Wuhan University of Technology, Wuhan 430070, China
}

Correspondence should be addressed to Denghui Liu; 293203@whut.edu.cn

Received 25 December 2020; Revised 22 April 2021; Accepted 1 July 2021; Published 12 July 2021

Academic Editor: Mosbeh Kaloop

Copyright (C) 2021 Jingyi Guo et al. This is an open access article distributed under the Creative Commons Attribution License, which permits unrestricted use, distribution, and reproduction in any medium, provided the original work is properly cited.

Commodity housing is the most important product in the development of modern civil engineering, and it is also the frontier problem of modern engineering project management research. The progress of civil engineering in China can be seen to a great extent through the development of commercial housing. In order to solve the severe problem of rapid growth of commodity housing price in China, considering the advantages of system dynamics theory, a system dynamics model of commodity housing price is constructed. Eight subsystems, namely, housing demand, housing supply, housing price, urban population, urban economy, housing land, housing tenancy, and macro-control, are studied. Taking the relevant data of Wuhan as an example, the Vensim DSS is used for simulations. In addition, a validity test and sensitivity test are used to verify the validity and feasibility of the model, respectively. Based on the model, it is successfully predicted that the price of commercial housing in Wuhan will reach $18,207.9$ yuan $/ \mathrm{m}^{2}$ in 2030 , which provides a more systematic method of prediction for synthesis simulation of commercial housing markets. From the perspective of the developer loan interest rate, real estate tax rate, purchase restriction, and other policies, we show that the developer loan interest rate regulation policy has the strongest effect on guiding the change in commercial housing prices in Wuhan. Generally, this study provides insight into the responses that the national government could use to control housing prices.

\section{Introduction}

Commercial housing price is a major livelihood issue that has attracted much public attention, and it is also a hot issue in the field of engineering projects. The daily lives of residents are highly dependent on housing. Because of the special national conditions in China, houses are generally purchased with savings. Hence, discussion of the fundamental causes of changes in housing prices and effective control over their rapid increase are key to the sustainable and healthy development of the housing industry as well as the maintenance of social stability.

Predictions on housing prices not only provide references for house purchasers to make decisions, but they also provide references for relevant departments to formulate further policies. Selecting appropriate methods for predicting commercial housing prices and future trends of prices is critically important. This paper summarizes several models of housing price prediction by reviewing the results of previous research conducted both inside and outside of China, including regression analysis [1], time sequence model [2], gray prediction model [3], BP neural network model [4], and system dynamics model.

Various features of commercial residential buildings, such as immobility, high value, value preservation, and growth, and the interaction of these features can affect prices, and these relationships are difficult to explain using the traditional methods of mathematical studies. For example, the regression analysis model is only suitable for medium-term predictions; the time sequence model does not consider the influence of external factors; the gray prediction model is less accurate for medium- and long-term 
predictions; and the BP neural network model may lead to overfitting. The system dynamics modeling principle can resolve this complex issue, as it does not have the shortcomings of other models.

Here, the method of system dynamics is used to build a model for urban commercial housing prices. With system simulation, the model predicts fluctuations in urban commercial housing prices. More generally, this paper provides a theoretical foundation through which the government could regulate commercial housing prices based on policy regulation and testing.

\section{Model Introduction}

In 1956, Professor J. W. Forrester of Massachusetts Institute of Technology first proposed the concept of system dynamics. In his book Industrial Dynamics (1961), he introduced the system dynamics model of famous electronic parts enterprises, which became the embryonic form of the system dynamics model and represented the early achievements of system dynamics. Since then, the research and practical application of system dynamics have developed rapidly; its theory, methods, and tools have been continuously improved; and its application direction has been expanding day by day, which has played an important role in dealing with many complex problems.

System dynamics model is a mathematical model established according to system dynamics theory, which uses special language and mathematical computer to simulate and analyze the problems of complex systems whose behaviors change with time. System dynamics model can analyze and study the system qualitatively and quantitatively. Contrary to the past functional simulation, it starts with the internal structure of the system, constructs the basic structure of the system, and then simulates and analyzes the dynamic behavior of the system.

Almost all the systems studied by system dynamics are multivariable systems. For multivariable systems, only by using the description method of state variables can the dynamic properties of the system be fully expressed, and it is precisely on the basis of the description of state variables that the internal laws and feedback mechanism of the system are further revealed.

System dynamics model has been developed for many years. With the continuous expansion of its application field and the development of its research depth, it has gradually become a core system discipline.

Based on the research purpose of this paper and the relevance of selected topics, this paper mainly discusses the research and development of system dynamics model in commodity housing price.

Foreign research on system dynamics model in commodity housing price mainly includes the system dynamics model constructed by Hendershott and Charlotte [5] consisting of five subsystems: economy, population variables, information transmission supply factors, location differences, and transaction frequency. Through simulation, it is concluded that economic information cost, supply cost, and expectation will affect commodity housing price. Balazs and
Mihaljek [6] studied the price of commercial housing based on the relevant data in Eastern Europe and established a system dynamics model including per capita GDP, real interest rate, housing credit, and population. The simulation results show that the housing market development system and housing finance quality have great influence on the price of commercial housing. Markus discussed the relationship between the urban population structure and the demand for commercial housing through the system dynamics model. Hwang et al. [7] established a system dynamics model to analyze the relationship between supply and demand, housing price, and mortgage loan policy. The research results show that when the housing demand is too large, adjusting the loan policy can limit the price increase of commercial housing to a certain extent.

Based on China's national conditions, the price of commercial housing is closely related to the national economy, and it is also a major livelihood issue. Compared with foreign countries, the system dynamics research on the price of commercial housing in China is more mature, mainly including the following: Ji [8] sought the main factors affecting the price of commercial housing from the aspects of price composition, supply and demand, macro-economy, and policy; defined three subsystems of land supply, housing supply, and housing price according to the historical data of Nanjing commercial housing market; and established a system dynamics simulation model to predict the trend of housing price. Wang and Wang [9] divided the housing market system into four subsystems: housing demand, housing supply, housing price, and land supply and simulated and predicted the housing market system in Xi' an from 2001 to 2015 . The results show that the model can closely reflect the historical development and reality of Xi'an housing industry. Tu and Huang [10] took Nanchang real estate housing market as the research object; systematically analyzed the mutual influence between the price and the relationship between supply and demand of commercial housing market; built a commercial housing market model from the five subsystems of urban population, economic development, housing demand, housing supply, and housing price for simulation experiments; and predicted and analyzed the future housing price and demand trend. Chen and Liao [11], aiming at the actual situation of Wuhan commercial housing market, comprehensively considered various factors affecting its price; established corresponding models by using system dynamics; and simulated, analyzed, and obtained the changing trend of Wuhan commercial housing price and its related influencing factors. Chen [12] established a system dynamics model including housing supply and demand, national income, population, housing security scale, and land stock to study the development trend of commercial housing prices in Xiangtan City. It is considered that controlling land price and adjusting the structure of supply and demand of real estate and the interest rate of deposit and loan are effective means to control house price. Shen and Ma [13] divided the housing market into four subsystems: population, demand, supply, and price, and conducted a system dynamics simulation study on the housing price in Shanghai. It was found that the most 
important factor that led to the continuous increase of housing price in Shanghai in recent years was the excessive investment demand, which led to a serious imbalance between supply and demand. Ma [14] divided the commercial housing market in Hangzhou into three subsystems: price, supply, and demand; established a system dynamics simulation model; and found that system dynamics can simulate the house price well.

Compared with other research methods, system dynamics has the following advantages: (1) It can conveniently simulate complicated systems (e.g., it can analyze and verify factors that cannot be easily quantified by the social economy). (2) It does not have strict requirements for data (e.g., systems lacking historical data can still be analyzed). (3) It can clearly demonstrate the implicit and explicit feedback circuits within the system. (4) It can be used to conduct dynamic simulation experiments with different parameters and examine the varying statuses and variation trends of the system.

The commercial housing market involves multiple stakeholders and various factors, such as governments, property developers, house purchasers, and financial institutions, which make up a highly complicated socioeconomic system. System dynamics can be used to resolve such complexity.

The establishment of a reasonable and valid system dynamics model can facilitate analysis of the relationship between the factors that influence commercial housing prices and their degree of impact on the system. The system dynamics model vividly demonstrates the systematic issues both in terms of data and structure.

Through literature review, it can be concluded that the system dynamics model is very mature in the study of commodity housing price forecasting, and scholars at home and abroad mostly choose the subsystems of housing supply, housing demand, population, economy, and land use to build the dynamic model and have achieved corresponding research results. However, in the process of literature research, some problems have also been found: most scholars only selected several mainstream subsystems, such as urban population, economic development, housing demand, housing supply, and housing price. This choice is not comprehensive.

In recent years, with the influx of migrants into cities and the soaring prices of commercial housing, some people have no choice but to "sublet from purchase," which makes the housing rental market develop significantly and has now become an indispensable component of housing supply [15]. The level of rent will force renters to compare their relationship with house price. When the ratio of rent to house price is too high, it is not cost-effective to rent a house, and renters prefer to buy their own houses. At the end of 2017, the Central Economic Work Conference proposed to "speed up the establishment of a housing system with multisubject supply, multichannel security and rent-and-purchase simultaneously." It is necessary to develop the housing leasing market, especially long-term leasing, protect the legitimate rights and interests of leasing stakeholders, and support the development of specialized and institutionalized housing leasing enterprises [16]. It can be seen that the status of the residential rental market is getting higher and higher, and it has gradually become an effective supplement to the primary residential market. Therefore, when studying the price fluctuation of commercial housing, it is necessary to study the housing leasing subsystem.

The macro-control policy in the commodity housing market is an important means for the government to regulate and manage the commodity housing market and keep the commodity housing price fluctuating within a reasonable range. By studying and combining the regulation and control policies of commercial housing for more than ten years, we can find that China has formed a policy regulation and control system with tax policy, monetary and financial policy, house purchase policy, and land policy as the main means of regulation and control. Various policies restrict different participants in the transaction process of commercial housing and adjust the price of commercial housing by fundamentally adjusting the ratio of supply and demand of commercial housing. Therefore, when studying the price fluctuation of commercial housing, the research on macrocontrol subsystem is also an essential part.

Therefore, taking advantage of system dynamics, this paper improves and supplements the existing research and puts forward the research model.

\section{Materials and Methods}

3.1. Main Steps of System Dynamics Model. The basic mechanism in the system dynamics model is the first-order feedback loop. A complex system is composed of these interactive feedback loops.

It can be divided into the following steps to solve the problem with system dynamics model [17].

3.1.1. Analysis of Research Objects. The main tasks of this step are as follows: use the theory of system dynamics to systematically and comprehensively understand and analyze the studied object; clarify the problems to be solved; delineate the boundaries of the system preliminary; and determine each variable.

3.1.2. Analysis of System Structure. The main tasks of this step are as follows: analyze the structure of the system; divide the hierarchy and subsystem of the system; and determine the overall and local feedback mechanism.

\subsubsection{Construction of System Dynamics Model and Drawing} of System Flow Chart. The main tasks of this step are as follows: use the related software of system dynamics to model and draw system flow chart; establish the mathematical function relationship between the main variables; determine and estimate various parameters; and assign values to table functions.

In the process of modeling with Vensim software, it is necessary to establish correct equations among variables to calculate the values of each variable. Besides general curve 
function, commonly used functions include conditional function, delay function, pulse function, and lookup function.

The following will introduce and explain the principles of these functions [17].

(1) Conditional function.

Conditional function is a kind of logical function. The conditional function provided in software Vensim is

$$
\text { IF ELSE THEN (cond, ontrue, onfalse). }
$$

This function is usually called conditional function. When the condition "cond" is true, it returns "ontrue" value. Otherwise, "onfalse" value is returned. The "cond" is usually an expression, and "ontrue" or "onfalse" can also be an expression.

IF ELSE THEN (cond, ontrue, onfalse)=ontrue, when "cond" is true.

IF ELSE THEN (cond, ontrue, onfalse)= onfalse, when "cond" is false.

(2) Delay function.

The system dynamics model contains the main material and information flow in the feedback system, and sometimes there is delay between the material and information flow. For example, the investment in production cannot be immediately profitable; when people get sick, they usually have to go through the latent period before they show symptoms of illness.

Delay plays an important role in the structure of information feedback system. The delay function provided in software Vensim is

DELAY1 (input, delaytime, initial value).

(3) Pulse function.
Pulse function provides a method of instantaneous impact, which describes the independent change of variables in real life; that is, the variables return to their original values after each change.

The pulse function provided in software Vensim is

$$
\text { PULSE( start, width). }
$$

(4) Lookup function.

It is often necessary to describe the nonlinear relationship between some variables in the model, which is difficult to realize by simple combination of operations between variables. However, it is convenient to give this nonlinear relationship graphically. Software Vensim can realize this function through lookup function.

The general steps to establish a lookup function are as follows:

(1) Determine independent variables and dependent variables in lookup function.

(2) Define the range of variable values, which is usually determined by historical data and predicted data.

(3) Select appropriate curve endpoints, stagnation points, inflection points, etc. For example, if the dependent variable is an influence factor in a $[0,1]$ interval, the point where the dependent variable is equal to 0 or 1 is obviously to be marked.

(4) Make graphics, usually using $X$ axis to represent independent variables and $Y$ axis to represent dependent variables.

Note. Lookup function curve is not a smooth curve; it is also realized by discretization. The mathematical description of lookup functions in Vensim is as follows:

WITH LOOKUP $([(X \min , X \max )-(Y \min , Y \max )],(X 1, Y 1),(X 2, Y 2), \ldots,(X n, Y n))$.

3.1.4. Inspection and Evaluation of the Model. The key to judge the advantages and disadvantages of the system dynamics model is to test whether the model can truly and effectively reflect the history, as well as analyze and predict the development trend of future events as accurately as possible. The main task of this step is to test the validity and sensitivity of the model. Only after passing the tested model can the next model simulation be carried out.

\subsubsection{Simulation and Policy Analysis with the Help of Model} Software. The main tasks of this step are as follows: model simulation and policy analysis are carried out under the guidance of the theory of system dynamics, and then the problems of the system are deeply analyzed; find the decision to solve the problem.

\subsection{Model Building}

3.2.1. Analysis of Research Objects. Fluctuations in commercial housing prices are fundamentally determined by the supply-demand relationship, which is also the reason of multiple factors and participants involved in the commercial housing market. Analysis of the commercial housing price system leads to the selection of some primary factors that impact commercial housing prices for relation analysis of the system model. 
Profit rate of development, bank support, and vacancy rate are the main factors affecting the supply of commercial housing.

Residential demand mainly includes rigid demand and investment demand. The factors that affect these two demands mainly include the following: per capita living space, number of marriages, number of families, ratio of house price to income, scale of affordable housing construction, number of households relocated, number of high-income families, and total newly added population.

The price of commercial housing mainly consists of land cost, construction and installation expenses, period cost, tax, and profit. Land cost and construction cost are important components, and their changes will directly lead to changes in housing prices. These factors have an impact on housing prices in terms of cost composition.

The change of urban population is determined by four indicators: birth population, death population, immigrant population, and emigration population.

Macro-economy and commodity housing price interact with and influence each other.

The main influencing factors of residential land are land price and land supply. As an important part of commodity housing price, the rise of residential land price will inevitably lead to the rise of house price. Moreover, in China, because land ownership belongs to the state, the supply of land determines the supply of commercial housing. At present, the land price is constantly rising, and the land acquisition cost of developers is also increasing. The scarcity of development land directly affects the development and operation ability of residential development enterprises, which leads to limited housing supply. However, with the increasing demand, the demand is in short supply, which will inevitably lead to an increase in the price of commercial housing.

The main influencing factor of housing lease is rent.

China's commercial housing market can be directly intervened by the government. Therefore, various policies formulated by the government can limit and regulate the fluctuation of commercial housing prices from taxation, finance, land, and other aspects.

The commercial housing market of Wuhan is the focal market of study. The sample data used range from 2003 to 2017. The data were obtained from the Wuhan Statistical Yearbook and the National Bureau of Statistics. The relationships between the variables are mostly expressed by a logic function, condition function, delay function, table function, and impulse function in the system dynamics model.

3.2.2. Division of Subsystems. The existing subsystems about commodity housing price research are not comprehensive. On this basis, this paper makes supplements and innovations, adding the housing leasing subsystem and the macrocontrol policy subsystem, and explains the reasons for choosing these two subsystems. The related contents have been explained in Section 2.

Eight subsystems, namely, housing demand, housing supply, housing price, urban population, urban economy, housing land, housing tenancy, and macro-control, are studied and built, with Vensim DSS software simulation, to obtain the cause-and-effect feedback diagram of the system.

(1) Residential Supply Subsystem. Figure 1 shows the causal feedback relationship between the indicators of the residential supply subsystem. There are 6 feedback loops about the total supply of housing, and the main feedback loop is negative feedback. It can be seen from this loop that the increase of total housing supply will increase the ratio of housing supply and demand, while the oversupply will lead to a decrease in the price of commercial housing, which will reduce the development profit rate, thus reducing the developer's willingness to develop housing, resulting in a decrease in the transaction area of residential land, resulting in a decrease in the newly started residential area, the unsold construction area, and the completed residential area, which will eventually lead to a decrease in total housing supply.

(2) Housing Demand Subsystem. Figure 2 shows the causal feedback relationship between the indicators of the residential demand subsystem. There are 15 feedback loops related to the residential demand subsystem. Take one feedback loop as an example to illustrate the influence mechanism: the increase of total housing demand will reduce the ratio of housing supply and demand, and the shortage of supply will lead to the rise of commodity housing prices, which will prompt the state to strengthen macropolicy control and promote the implementation of monetary and financial policies, increase the mortgage interest rates of one suite, and reduce the rigid demand of consumers' housing, thus reducing the total housing demand.

(3) Housing Price Subsystem. Figure 3 shows the causal feedback relationship between the indicators of the housing price subsystem. There are 8 feedback loops about housing price, and the main feedback loop is negative feedback. It can be seen from this loop that the higher the price of commercial housing, the greater the development profit, thus increasing the developer's willingness to develop housing, which will expand the investment scale of commercial housing. Therefore, in the land acquisition stage, the transaction area of residential land will increase, resulting in an increase in the newly started residential area, an increase in the construction area without presale, and an increase in the completed residential area, resulting in an increase in the total residential supply and an increase in the ratio of residential supply and demand.

(4) Urban Population Subsystem. Figure 4 shows the causal feedback relationship between the indicators of the urban population subsystem. There are two feedback loops about the total population, and the main feedback loop is positive feedback. From this loop, we can see that, in the case of a fixed family population, the larger the total population, the more the households, the greater the rigid demand for housing, and the greater the total demand for housing. When the demand increases, the price of commercial housing rises, the transaction volume of housing increases, 


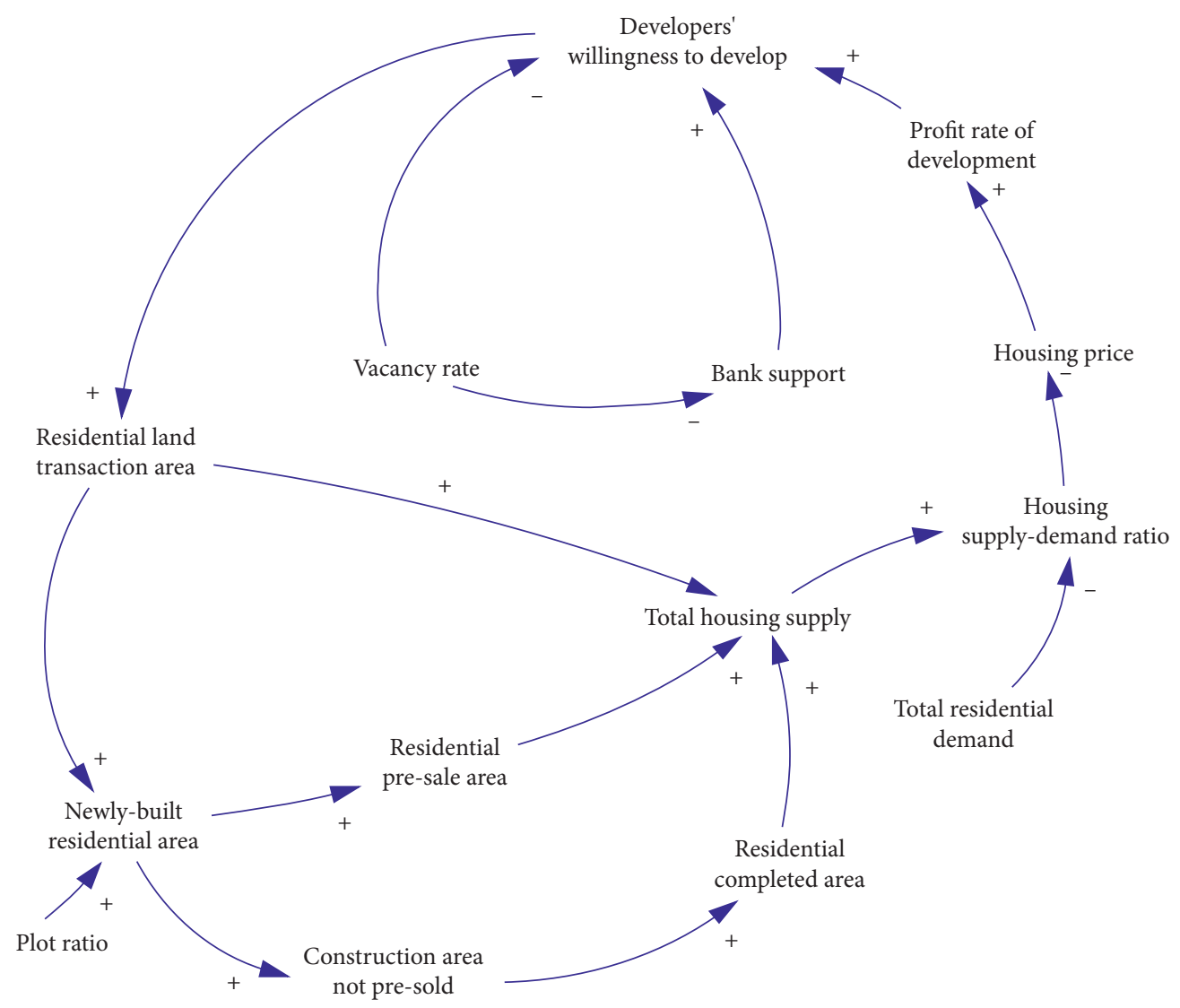

FIGURE 1: Causality diagram of residential supply subsystem.

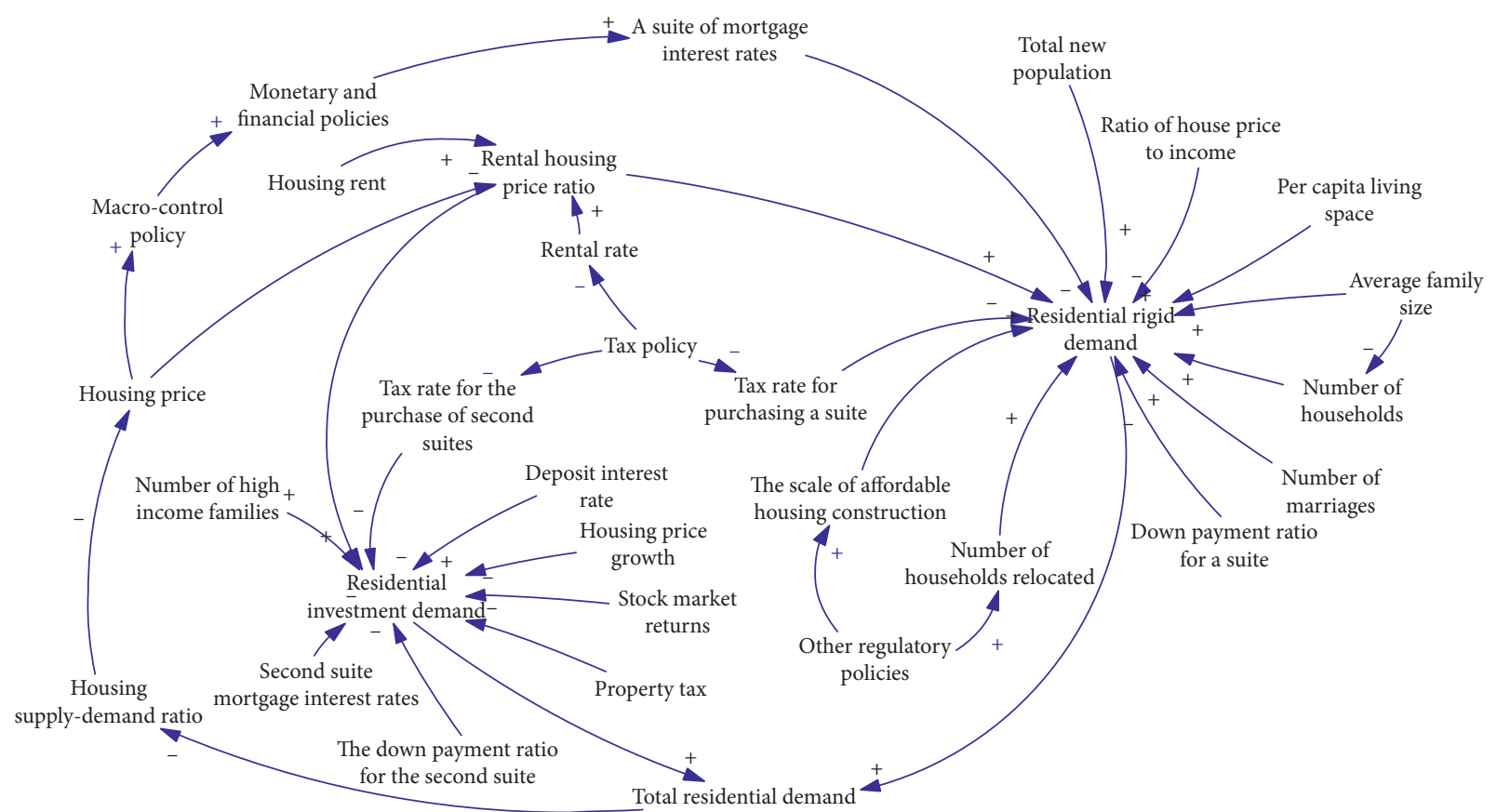

Figure 2: Causality diagram of housing demand subsystem. 


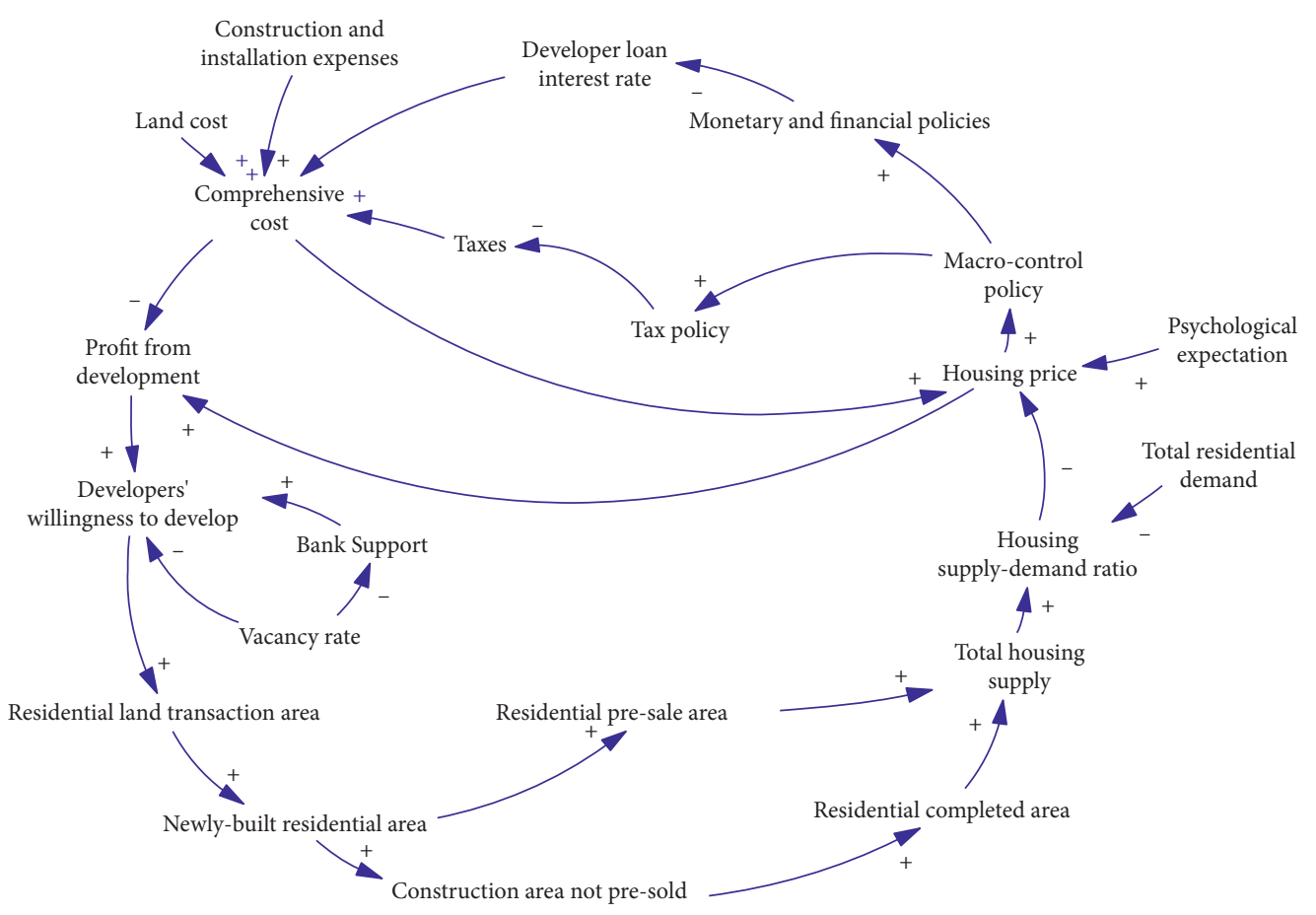

FIGURE 3: Causality diagram of housing price subsystem.

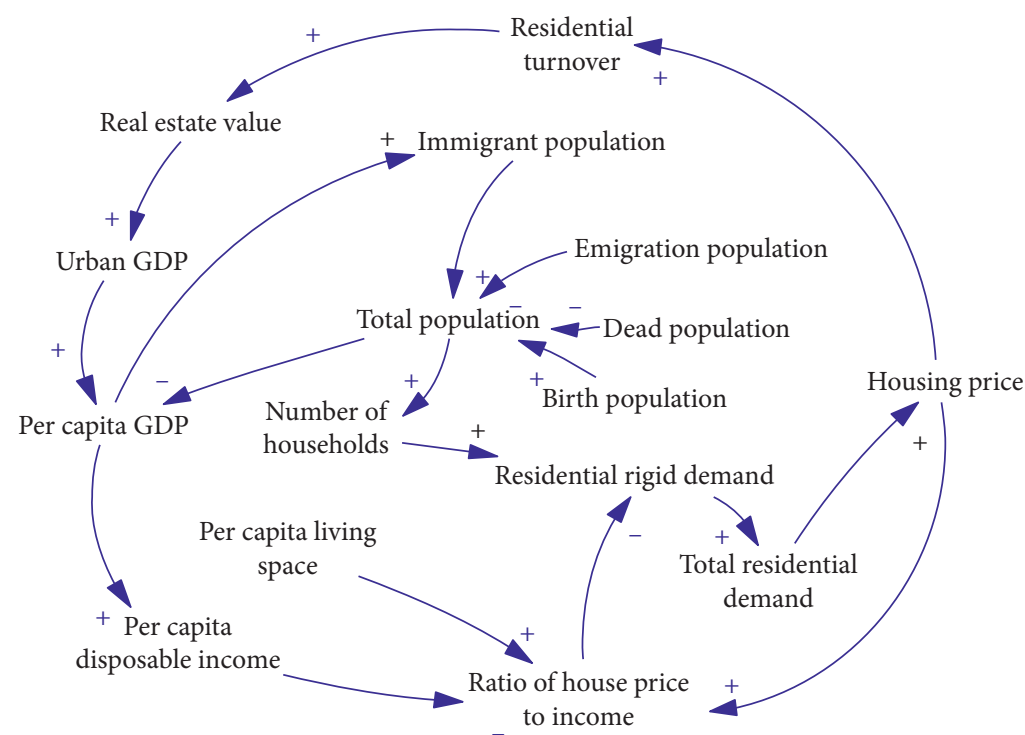

FIGURE 4: Causality diagram of urban population subsystem.

the value of real estate industry increases, the urban GDP increases, and the per capita GDP also increases. Urban economic growth and high-income level of residents will attract migrants to work, the number of migrants will increase, and eventually the total population will increase.

(5) Urban Economic Subsystem. Figure 5 shows the causal feedback relationship between the indicators of the urban economic subsystem. There are two feedback loops about urban GDP, and the main feedback loop is positive feedback.
It can be seen from this loop that the higher the urban GDP, the higher the per capita GDP, and the higher the per capita disposable income, the lower the ratio of house price to income, which leads to the increase of rigid demand and total demand of housing. The increase in demand leads to a decrease in the ratio of housing supply and demand, while the price of commercial housing rises when supply is less than demand, thus increasing the transaction volume of housing, the value of real estate industry, and the growth of urban economy. 


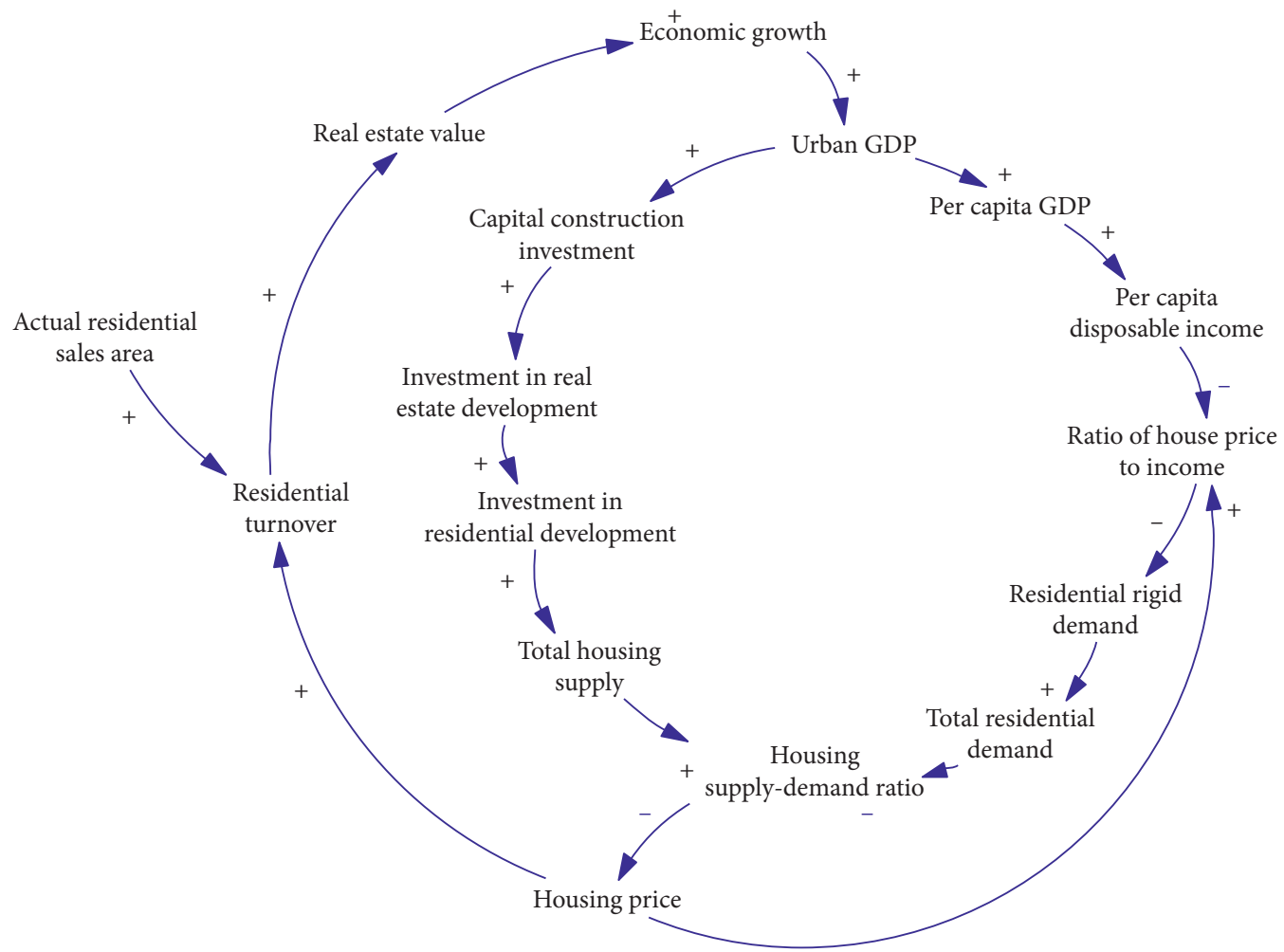

Figure 5: Causality diagram of urban economic subsystem.

(6) Residential Land Subsystem. Figure 6 shows the causal feedback relationship between the indicators of the residential land subsystem. There are two feedback loops about residential land price, and the main feedback loop is negative feedback. It can be seen from this loop that the land price leads to higher cost for developers to purchase land, higher comprehensive cost of commercial housing development, and higher housing price. The rising price of commercial housing will prompt the country to strengthen macro-policy control, promote the implementation of land policy, and directly control the decline of land price.

(7) Residential Leasing Subsystem. Figure 7 shows the causal feedback relationship between the indicators of the residential leasing subsystem. There are two feedback loops about the ratio of rent to house price; these two loops are negative feedback loops.

(8) Macro-Control Policy Subsystem. Figure 8 shows the causal feedback relationship between the indicators of the macro-control policy subsystem. The macro-control policies that will have an impact on the price of commercial housing mainly include the following aspects: tax policy, purchase policy, land policy, and other regulatory policies, such as population control policy and talent introduction policy.

In addition, in the face of the advancement of urbanization in China, the rigid demand for housing brought about by the renovation of large-scale shanty towns has increased, and the construction of affordable housing has shared a part of the rigid demand. All these behaviors need to be restrained and regulated by policies. The state has also made relevant policy constraints on housing loans with provident fund. Since this paper studies general commercial loans, it will not be repeated here.

3.2.3. Construction of Causal Feedback Diagram of Model. Through the analysis of subsystems in Section 3.2.2, we integrate eight subsystems and get the system dynamics causal feedback diagram of commodity housing price (Figure 9).

\subsubsection{Setting of Relevant Parameters and Construction of Relational Equations}

(1) Vacancy Rate $=0.1$. Vacancy rate refers to the ratio of vacant housing area to total housing area at a certain moment. According to the international common practice, the vacancy rate of commercial housing is $5 \%-10 \%$ as a reasonable area, and the vacancy rate is $10 \%-20 \%$ as a vacant dangerous area. In this paper, the critical value of 0.1 is taken as a constant value and brought into the software operation calculation. 


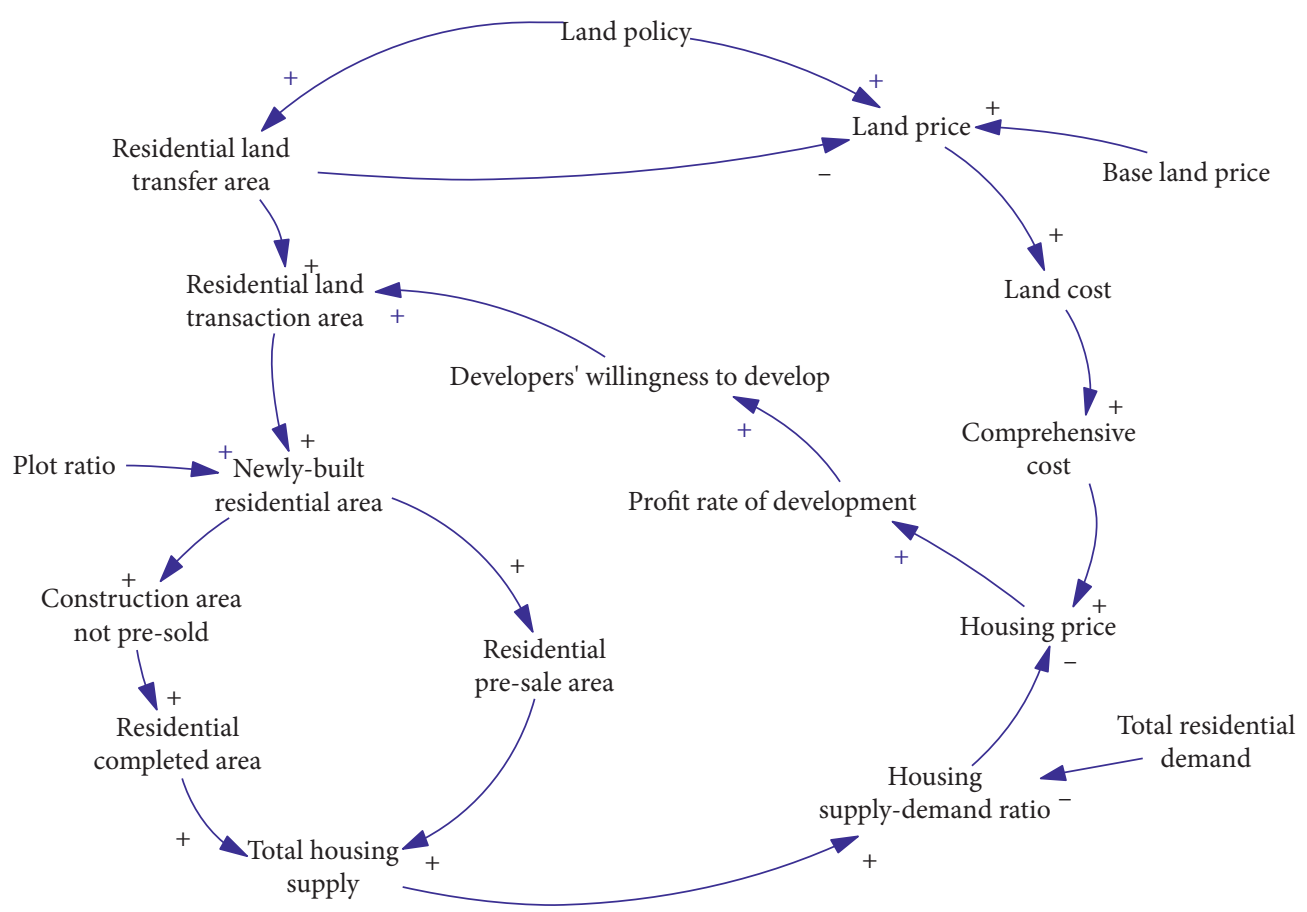

FIgURE 6: Causality diagram of residential land subsystem.

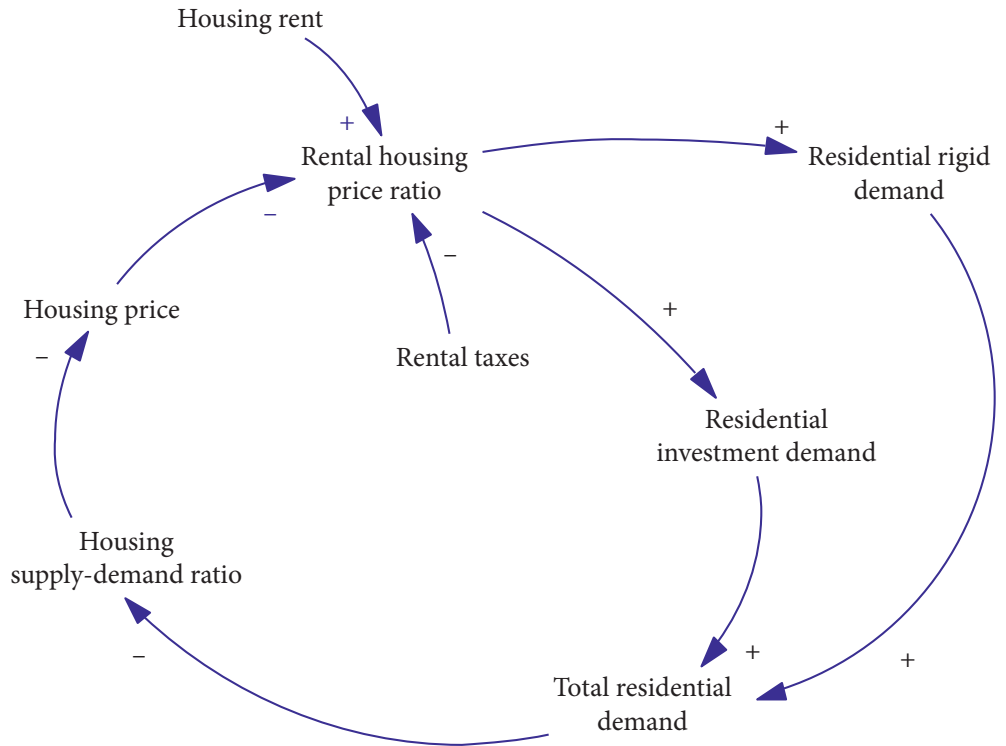

Figure 7: Causality diagram of residential leasing subsystem.

(2) Plot Ratio $=2.5$. The floor area ratio refers to the ratio of the total floor area to the land area. For developers, the floor area ratio determines the proportion of land price cost in the house, while for residents, the floor area ratio directly relates to the comfort of living. The floor area ratio is an important index to measure the use intensity of construction land. When the land is graded, the floor area ratio of Wuhan is assumed to be 2.5.
(3) Rental tax rate: before 2018, the value is 0.015 ; From 2018 , the rental tax rate $=0.015^{*}$ the rental tax rate control policy. In addition to paying value-added tax, surtax, and property tax, individuals also pay personal income tax when renting houses. Valueadded tax accounts for the main part. For individual rental housing, the value-added tax rate is $5 \%$, reduced by $1.5 \%$. Therefore, the rental tax rate is $1.5 \%$. 


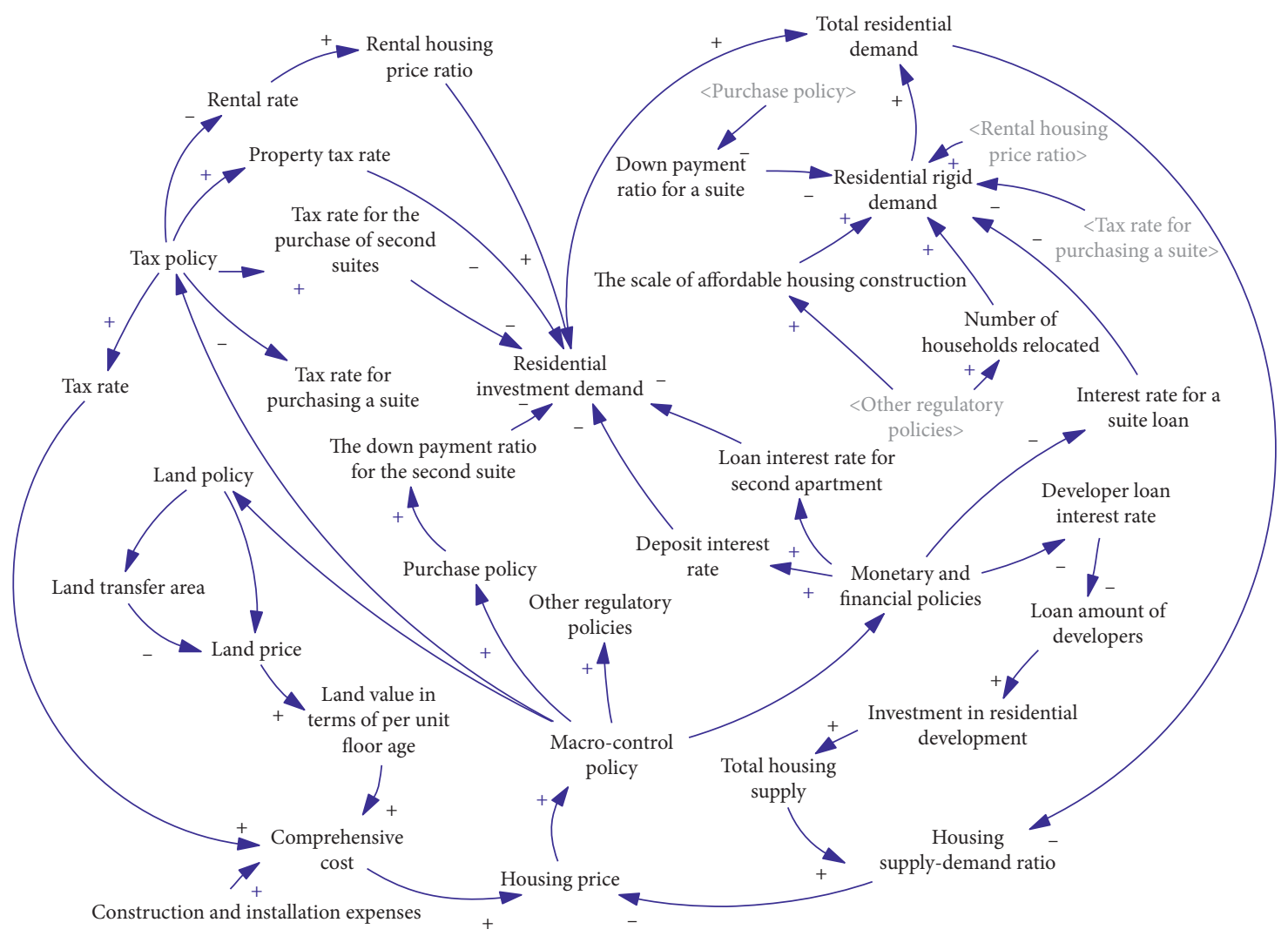

Figure 8: Causality diagram of macro-control policy subsystem.

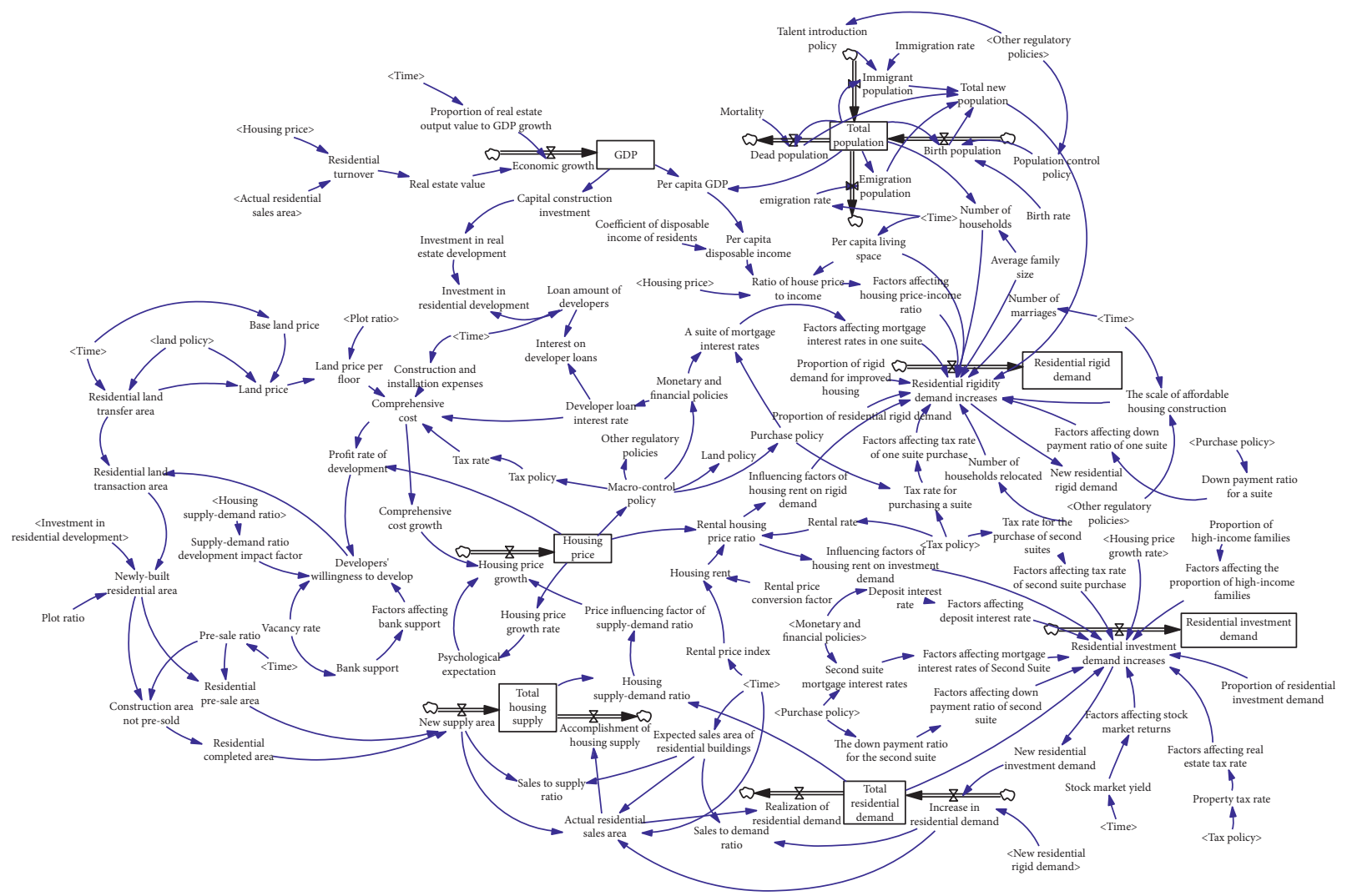

FIgURE 9: Flow chart of residential price system. 
(4) Residential presale area $=$ presale ratio $\times$ newly built residential area. Among them, the presale ratio is 0.8 . The most important way of selling commercial housing in China is the presale system. According to the relevant data of the National Bureau of Statistics, the proportion of the sales area (presale) of commercial housing in the total sales area has gradually increased from $63 \%$ in 2005 , and the presale proportion of 40 large and medium-sized cities has always remained above $80 \%$. Therefore, the presale ratio is 0.8 .

(5) Construction area not presold $=$ newly built residential area $\times$ (1- presale ratio).

(6) New residential rigid demand = residential rigidity demand increases.

(7) Land price per floor $=$ land price/plot ratio.

(8) Rent-house price ratio=housing rent/housing price.

The rent-to-house price ratio index is introduced to link the rental subsystem with the housing price.

(9) Housing rent $=$ rental price index $\times$ rental price conversion factor.

According to the Analysis Report of Wuhan Real Estate Market in 2003, the housing rent in Wuhan in 2003 was 380 yuan per square meter. However, data for other years cannot be obtained. However, from 2012 to 2018, the annual values of Wuhan commercial housing rental price index are 1054.40, $1139.42,1255.33,1266.25,1376.08,1433.17$, and 1434.42, respectively. Therefore, the rental price index in 2003 is calculated to be 488 by using the numerical values of these years to make a time series function. As the rent value in 2003 is known, the corresponding relationship between commercial housing rent and rental price index in $2003 \mathrm{can}$ be used to calculate the rent over the years. The coefficient in the functional relation is recorded as the rental price conversion coefficient, which can be known as 0.795 through the functional equation.

(10) Rental price conversion factor $=0.795 \times$ rental interest rate influence factor.

The rental interest rate impact factor is 1 in 2017 and before.

(11) Comprehensive cost $=$ (land price per floor+ construction and installation expenses $) \times$ $0.7 \times 2 \times$ developer loan interest rate + (land price per floor + construction and installation expenses $) \times(1+$ tax rate $)$.

According to the empirical data of real estate development, except land cost, construction and installation cost accounts for $65 \%$ of the development cost, $70 \%$ of the direct cost in the whole project development process needs to be supported by medium- and long-term loans from banks, and the average loan life is 2 years [18]. Therefore, the comprehensive cost formula can be defined from the above relationship. This formula is based on the definition and composition of comprehensive cost.

(12) New supply area $=($ residential presale area+ residential completed area)/0.45. Theoretically, the "new supply area" is equal to "(residential presale area + residential completed area)," but there is a certain deviation between the actual calculated data and the historical data. The main reason for this error is that the statistical caliber of each index data source is different. Therefore, through calculation and simulation, it can be divided by a correction coefficient of 0.45 , which can make the functional relationship equation hold.

(13) Residential land transaction area $=$ residential land transfer area $\times$ developers' willingness to develop housing $\times 0.83$. Theoretically, the "residential land transaction area" is equal to the residential land transfer area $\times$ developers' willingness to develop housing, but there is a certain deviation between the actual calculated data and the historical data. The main reason for this error is that the statistical caliber of each index data source is different, so it can be multiplied by a correction coefficient of 0.83 to make the functional relationship equation hold.

(14) Residential rigidity demand increases $=$ per capita living space $\times$ (number of households $\times$ proportion of rigid demand for improved housing $\times$ average family size + (number of marriages $\times 2 \times 0.8+$ number of households relocated $\times$ average family size $\times 0.5) / 10,000+$ total new population $\times$ proportion of residential rigid demand) $\times$ factors affecting mortgage interest rates of one suite $\times$ factors affecting tax rate of one suite purchase $\times$ factors affecting down payment ratio of one suite $\times$ factors affecting housing price-income ratio $\times$ influencing factors of housing rent on rigid demandthe scale of affordable housing construction.

According to Wuhan Statistical Yearbook, the average household population of urban residents in Wuhan from 2003 to 2017 was $3.03,2.99,2.87,2.85$, $2.88,2.92,2.92,2.90,2.89,2.88,2.71,2.64$, and 2.66 It can be seen that the average household population of urban residents in Wuhan has fluctuated around over the years. The "average family size" is 3 persons/household. 
Before 2018, the "number of households relocated" is 20,000. Beginning in 2018, the "number of households relocated" $=20,000 \times$ demolition policy. According to the survey, the total number of households involved in demolition in Wuhan in 2006 was 25,561, and the total number of households involved in demolition in 2007 was 16,960. Referring to the data processing methods of relevant literature, the average value of the data in these two years is taken as the number of relocated households in the past years, and 20,000 households are taken.

Specific data of per capita living area, number of households, marriage logarithm, and other indicators can be found in Wuhan Statistical Yearbook over the years. The introduction of a series of influencing factors is mainly for the convenience of the value test in the later test regulation. Before 2017, the value is 1 .

According to the calculation of urban housing demand, approximately $50 \%$ of the newly added population is estimated to have a demand for housing: $20 \%$ of the urban population is within the high-income and highest-income groups; $50 \%$ of the urban population has a demand for improved housing; $80 \%$ of the married population needs to buy a house; and $50 \%$ of the relocated population has a demand for housing [18].

(15) Land price $=((0.055719 \times$ residential land transfer area $+1.22197 \times$ base land price -259.521$) \times$ land price policy $+1200 \times$ PULSE $(2004,1)+2400 \times$ PULSE $(2005,1)+900 \times$ PULSE $(2007,1)-2500 \times$ PULSE $(2008,1)-2550 \times$ PULSE $(2009,1))$.

The formula “ $(0.055719 \times$ residential land transfer area $+1.22197 \times$ benchmark land price -259.521$) \times$ land policy" is obtained by data regression fitting, and the residual error is 0.92 . However, there are errors between the calculated results of 2004, 2005, 2007, 2008, and 2009 and the real data of the corresponding years. Therefore, it is corrected by pulse function. "(1200 $\times$ PULSE $(1,2004)$ " means that there was a pulse in 2004, which was 1 in 2004 and 0 in other years. 1200 is the difference from the real land price data in 2004.

Specific values are as follows:

For 2003, 2006, 2010-2017, the "land price" formula is " $(0.055719 \times$ residential land transfer area $+1.22197 \times$ base land price -259.521$) \times$ land price policy."

The "land price" in 2004 was " $(0.055719 \times$ resid ential land transfer area $+1.22197 \times$ base land price -259.521$) \times$ land price policy $+1200 \times 1$."

The "land price" in 2005 was “ $(0.055719 \times$ residential land transfer area $+1.22197 \times$ base land price -259.521$) \times$ land price policy $+2400 \times 1$."
The "land price" in 2007 was " $(0.055719$ $\times$ residential land transfer area $+1.22197 \times$ base land price -259.521$) \times$ land price policy + $900 \times 1$."

The "land price" in 2008 was " $(0.055719$ $\times$ residential land transfer area $+1.22197 \times$ base land price -259.521$) \times$ land price policy $-2500 \times 1$."

The "land price" in 2009 was " 0.055719 $\times$ residential land transfer area $+1.22197 \times$ base land price -259.521$) \times$ land price policy $2550 \times 1$."

(16) Investment in residential development $=0.5529 \times$ investment in real estate development $-66.477+$ loan amount of developers $+90 \times$ PULSE $(2003$, 3) $-100 \times$ PULSE $(2008,4)$.

The construction principle of this pulse equation is the same as that of the previous pulse function.

(17) Comprehensive cost growth=DELAY1I ((comprehensive cost-DELAY1 (comprehensive cost, 1)) $, \quad 1,100) \times 2+300 \times$ PULSE $\quad(2003,1)-600 \times$ PULSE $(2005,1)+500 \times$ PULSE $\quad(2006,1)-300 \times$ PULSE $(2007,1)+750 \times$ PULSE $(2008,1)+1350 \times$ PULSE $\quad(2009,1)+600 \times$ PULSE $\quad(2010,1)-$ $800 \times$ PULSE $(2011,1)-400 \times$ PULSE $(2013,1)-$ $1300 \times$ PULSE $(2016,1)$.

The equation is a logical equation. By default, the comprehensive cost increment is the comprehensive cost of this year minus the comprehensive cost of last year. " 1 " indicates a delay of 1 year, and " 100 " indicates the initial value of the comprehensive cost increase.

(18) Profit rate of development=IF THEN ELSE ((housing price-comprehensive cost)/comprehensive cost $\leq 0, \quad 0.2$, (housing price-comprehensive cost)/comprehensive cost) [19].

(Housing price-comprehensive cost)/comprehensive cost $=$ development profit rate. It is found that the historical data of housing price in some year is less than the comprehensive cost value of that year; that is, the development profit rate is less than 0 , which shows that the developer is at a loss, which should not happen in theory, because the ultimate goal of developers who develop commercial housing is to make profits. The possible reasons are as follows: the statistical caliber of residential price, floor price, and other indicators is inconsistent, or there is a problem with the average value of floor price and construction and installation cost. Therefore, when the calculated value of development profit rate is less than 0 , learn from the experience of existing research and take $20 \%$ uniformly; when the calculated value of the development profit rate is greater than 0 , the calculated value is taken. 
(19) Developer loan interest rate $=(0.0594+$ STEP $(0.0024,2008)-\operatorname{STEP}(0.0074,2013)) \times$ regulation policy of developer loan interest rate.

By looking up relevant data, it can be concluded that the annual weighted average interest rates of developers from 2003 to 2017 are $5.49 \%, 5.54 \%$, $5.76 \%, 6.04 \%, 6.89 \%, 7.26 \%, 5.40 \%, 5.61 \%, 6.25 \%$, $6.39 \%, 6.15 \%$. In order to reduce the error and facilitate the calculation, the average value is taken every five years. As a result, the annual "developer loan interest rate" was 5.94\% from 2003 to 2007. From 2008 to 2012, the annual "developer loan interest rate" was $6.18 \%$. From 2013 to 2017, the annual "developer loan interest rate" was $5.44 \%$.

Therefore, it can be known that the meaning of the above relational equation is as follows:

From 2003 to 2007, developer loan interest rate $=0.0594=5.94 \%$.

From 2008 to 2012, developer loan interest rate $=0.0594+0.0024=0.0618=6.18 \%$.

From 2013 to 2017, developer loan interest rate $=0.0594+0.0024-0.0074=0.0544=5.44 \%$.

(20) Price influencing factor of supply-demand ratio $=$ WITH LOOKUP (housing supply-demand ratio, $([(0,0)-(10,10)],(0,1.3),(0.2,1.2),(0.4,1.15)$, $(0.6,1.1), \quad(0.8,1.05), \quad(1,1), \quad(1.2,0.95), \quad(1.4,0.9)$, $(1.6,0.85),(1.8,0.8),(2,0.75),(2.2,0.7),(2.4,0.65)$, $(3.5,0.5)))$.

This is a lookup function. According to the actual data values of various indicators of commercial housing market in Wuhan over the years and referring to relevant literature, when the value of housing supplydemand ratio is different, the corresponding value is taken as the value of price influencing factor of supply-demand ratio. In the formula, $(1.4,0.9)$ means that when the ratio of housing supply and demand is 1.4 , the value of the price influencing factor of the ratio of supply and demand is 0.9 .

For convenience of understanding, it can be shown in table form (Table 1).

(21) Psychological expectation $=$ WITH LOOKUP (housing price growth ratio, $([(-0.6,0)-(10,10)]$, $(-0.6,0.3), \quad(-0.5,0.4), \quad(-0.4,0.5), \quad(-0.3,0.6)$, $(-0.2,0.7),(-0.1,0.8),(0,0.9),(0.1,1),(0.15,1.02)$, $(0.2,1.04),(0.3,1.06),(0.4,1.08),(0.5,1.1)))$.

This is a lookup function. According to the actual data values of various indicators of commercial housing market in Wuhan over the years and referring to relevant literature, when the housing price growth rate is different, the corresponding value is taken as the value of consumers' expected influence factor (psychological expectation). In the formula, $(-0.6,0.3)$ means that when the growth rate of housing price is -0.6 , the value of consumer expectation influencing factor (psychological expectation) is 0.3 .
For convenience of understanding, it can be shown in table form (Table 2).

(22) Expected residential sales area $=$ WITH LOOKUP (time, $\quad([(2003,0)-(2030,8000)], \quad(2003,512.1)$, $(2004,613.91), \quad(2005,834.18), \quad(2006,908.92)$, $(2007,1069.89), \quad(2008,683.24), \quad(2009,1041.39)$, $(2010,1095.22), \quad(2011,1182.21), \quad(2012,1390.47)$, $(2013,1750.43), \quad(2014,1978.96), \quad(2015,2413.77)$, (2016,2931.06), $\quad(2017,3085.78), \quad(2018,3269.61)$, $(2019,3453.45), \quad(2020,3637.28), \quad(2021,3821.12)$, $(2022,4004.95), \quad(2023,4188.79), \quad(2024,4372.62)$, $(2025,4556.45), \quad(2026,4740.29), \quad(2027,4924.12)$, (2028,5107.96), (2029,5291.79), (2030,5475.63)))

This is a lookup function about time.

For convenience of understanding, it can be shown in table form (Table 3).

Among them, the data from 2003 to 2017 is equal to the actual residential sales area, and the data from 2018 to 2030 is the expected residential sales area.

For the lookup functions of time in the model, most of them choose the time series prediction method to get the predicted value. Choose the famous ARIMA model when building the model. The ARIMA model is called autoregressive integrated moving average (ARIMA) model. The socalled ARIMA model refers to a model established by transforming a nonstationary time series into a stationary time series and then regressing only its lag value as well as the present value and lag value of the random error term.

When ARIMA model is used for forecasting, the most important step is to test the variance, trend, and seasonal variation rule of time series with $\mathrm{ADF}$ unit root according to scatter diagram, autocorrelation function, and partial autocorrelation function diagram and to identify the stationarity of time series. Generally speaking, the time series of economic operation is not a stationary series.

When using time series models, such as ARMA and ARIMA, the time series is required to be stable. Therefore, when studying a period of time series, the first step is to carry out the stationarity test. Besides the naked eye test method, the more commonly used strict statistical test method is ADF test, which is also called unit root test. The full name of ADF test is Augmented Dickey-Fuller test. When the sequence has high-order lag correlation, ADF test can be used. Its principle is to judge whether the sequence has unit root: if the sequence is stable, there is no unit root; otherwise, there will be a unit root. Therefore, the H0 hypothesis of ADF test is that there is a unit root. If the statistics of significance test result are less than three confidence levels $(10 \%, 5 \%, 1 \%)$, the original hypothesis should be rejected with the assurance of $(90 \%, 95,99 \%)$ [20].

Take the table function of expected residential sales area as an example. The historical value of expected sales area in Wuhan from 2003 to 2017 is known from Wuhan Statistical Yearbook over the years. (Note. There is an assumption here, assuming that the expected sales area of commercial housing is fully realized from 2003 to 2017 and the expected value is the actual sales area.) Table 4 shows the relevant data. 
TABLE 1: Table function of price influencing factor of supply-demand ratio.

\begin{tabular}{|c|c|c|c|c|c|c|c|c|c|c|c|c|c|c|}
\hline Supply-demand ratio & 0 & 0.2 & 0.4 & 0.6 & 0.8 & 1 & 1.2 & 1.4 & 1.6 & 1.8 & 2.0 & 2.2 & 2.4 & 3.5 \\
\hline Degree of influence on price & 1.3 & 1.2 & 1.15 & 1.1 & 1.05 & 1 & 0.95 & 0.9 & 0.85 & 0.8 & 0.75 & 0.7 & 0.65 & 0.5 \\
\hline
\end{tabular}

TABLE 2: Table function of psychological expectation influencing factors.

\begin{tabular}{|c|c|c|c|c|c|c|c|c|c|c|c|c|}
\hline $\begin{array}{ll}\text { syc } \\
\text { egr }\end{array}$ & $\begin{array}{c}-0.6 \\
0.3\end{array}$ & -0 & -0 & $\begin{array}{c}-0.3 \\
0.6\end{array}$ & $\begin{array}{c}-0.2 \\
0.7\end{array}$ & $\begin{array}{c}-0.1 \\
0.8\end{array}$ & $\begin{array}{c}0 \\
0.9\end{array}$ & $\begin{array}{c}0.1 \\
1\end{array}$ & & & & 0.4 \\
\hline
\end{tabular}

TABle 3: Table function of expected residential sales area.

\begin{tabular}{|c|c|c|c|c|c|c|c|}
\hline year & 2003 & 2004 & 2005 & 2006 & 2007 & 2008 & 2009 \\
\hline Expected residential sales area & 512.1 & 613.91 & 834.18 & 908.92 & 1069.89 & 683.24 & 1041.39 \\
\hline Year & 2010 & 2011 & 2012 & 2013 & 2014 & 2015 & 2016 \\
\hline Expected residential sales area & 1095.22 & 1182.21 & 1390.47 & 1750.43 & 1978.96 & 2413.77 & 2931.06 \\
\hline Year & 2017 & 2018 & 2019 & 2020 & 2021 & 2022 & 2023 \\
\hline Expected residential sales area & 3085.78 & 3269.61 & 3453.45 & 3637.28 & 3821.12 & 4004.95 & 4188.79 \\
\hline Year & 2024 & 2025 & 2026 & 2027 & 2028 & 2029 & 2030 \\
\hline Expected residential sales area & 4372.62 & 4556.45 & 4740.29 & 4924.12 & 5107.96 & 5291.79 & 5475.63 \\
\hline
\end{tabular}

TABLE 4: Residential sales area in Wuhan over the years.

\begin{tabular}{|c|c|c|c|c|c|c|c|c|}
\hline Year & 2003 & 2004 & 2005 & 2006 & 2007 & 2008 & 2009 & 2010 \\
\hline Expected residential sales area & 512.10 & 613.91 & 834.18 & 908.92 & 1069.89 & 683.24 & 1041.39 & \\
\hline Year & 2011 & 2012 & 2013 & 2014 & 2015 & 2016 & 2017 & 1095.22 \\
\hline Expected residential sales area & 1182.21 & 1390.47 & 1750.43 & 1978.96 & 2413.77 & 2931.06 & 3085.78 & \\
\hline
\end{tabular}

The unit of expected residential sales area is 10,000 square meters.

The sales area of commercial housing is recorded as "area." Bring the relevant data in Table 1 into EViews software for model simulation.

(1) Area Stationarity Test. In Table 5, the first row is the obtained $t$ value and $P$ value, and the following three rows are the critical values of $t . P$ value is the probability value corresponding to $t$-statistic, so it is enough to look at $P$. $P$ value should be less than the given significance level, generally $0.05,0.01$, etc. The closer $\mathrm{P}$ to 0 , the better. However, from the test results, the $P$ value is 0.9524 , which rejects the original assumption that there is no unit root, and the variable has unit root, which is a nonstationary sequence.

Therefore, it is necessary to make first-order difference to the variables. The stability test results of the first-order difference of variables are as follows.

From the test results in Table 6 , the $P$ value is $0.0328<-3.11991$, and at the critical level of $5 \%$, the original assumption that there is no unit root is accepted; that is, the first-order difference of variables is divided into stationary sequences.

(2) Autocorrelation and Partial Autocorrelation Test. Autocorrelation coefficient (AC) and partial autocorrelation coefficient (PAC) are the concepts defined in statistics, which are the statistical indicators to reflect the correlation
TABle 5: ADF test of expected residential sales area.

\begin{tabular}{lccc}
\hline & & $t$-Statistic & Prob. \\
\hline $\begin{array}{l}\text { Augmented Dickey-Fuller test } \\
\text { statistic }\end{array}$ & & -0.687638 & \\
& $1 \%$ level & -4.80008 & \\
Test critical values & $5 \%$ level & -3.791172 & 0.9524 \\
& $10 \%$ & & \\
& level & -3.342253 & \\
\hline
\end{tabular}

TABLE 6: ADF test of first-order difference of residential expected sales area.

\begin{tabular}{lccc}
\hline & & $t$-Statistic & Prob. \\
\hline $\begin{array}{l}\text { Augmented Dickey-Fuller test } \\
\text { statistic }\end{array}$ & & -3.367558 & \\
& $1 \%$ level & -4.05791 & \\
& $5 \%$ level & -3.11991 & 0.0328 \\
Test critical values & $10 \%$ & & \\
& level & -2.701103 & \\
\hline
\end{tabular}

degree between variables, but the relationship between specific variables expressed by them is different.

When studying the influence of one variable on another, if the influence of other variables is considered at the same time, the degree of the relationship between variables is 
called autocorrelation coefficient. If one variable is influenced by another, the other influencing variables are regarded as constants; that is, the influence of other factors is not considered for the time being, and the relationship between these two variables is considered separately. At this time, the partial correlation coefficient is used to analyze the relationship between variables.

Autocorrelation and partial autocorrelation are used to measure the correlation between current series values and past series values and indicate the most useful past series values when predicting future values. By understanding this content, we can determine the sequence of processes in ARIMA model.

Figure 10 shows the autocorrelation and partial autocorrelation of the first-order difference sequence of variable area.

It can be seen from Figure 10 that there is no autocorrelation or partial autocorrelation in the first-order difference sequence of variable area. Therefore, the $P$ value and $q$ value in ARIMA (p,d,q) model are both 0 .

(3) ARIMA Model Construction. According to the test results of autocorrelation and partial autocorrelation, ARIMA $(0,1,0)$ model is constructed, and the results are as shown in Table 7.

(4) Carrying Out Residual Autocorrelation and Heterosexuality Test on the Fitting Results. The Results are as shown in Table 8. From the test results in Table 8 , the $P$ values of the two statistical variables are greater than 0.05 (one is 0.6273 , and the other is 0.5661 ). This means that, at the critical level of $5 \%$, the residual sequence does not have autocorrelation.

From the test results in Table 9, the $P$ values of the two statistical variables are both greater than 0.05 (one is 0.7277 , and the other is 0.6994). This means that, at the critical level of $5 \%$, there is no $\mathrm{ARCH}$ effect in the residual sequence; that is, there is no heteroscedasticity in the variables.

According to the test results, the constructed model is effective and robust and can be used for prediction.

(5) Model Prediction Using the Constructed Model. The area data from 2018 to 2030 is predicted, and the results are shown in Table 10.

\subsubsection{Simulation Results and Model Test}

(1) Effectiveness Test. Vensim DSS software is used to simulate and calculate the residential data from 2003 to 2017 and predict the specific values of the main indicators from 2018 to 2030 [21].

The simulation effect of the model can be verified by the relative error between the historical value and the simulation value.

Relative errors are less than (Table 11). Only three years show errors greater than $5 \%$. Thus, the system dynamics model of commercial housing prices is robust.

(2) Sensibility Test. In the system dynamics model, the relationship between the factors is complicated, but the relationships between parameters are simple by comparison.
Gathering historical data and utilizing certain mathematical methods are necessary for obtaining the relationship equation between variables. When determining the coefficients of the equation, the range of parametric variation can first be determined. Next, the parameters can be constantly revised within this range so that the output results match the historical data and the parameters can be determined. The sensibility test is used for parameter revision [22].

The sensibility test of the model is conducted using disposable household income as the coefficient: the coefficient of disposable household income is set at 0.32985 . The rigid demand increase index for housing was estimated when the coefficient of disposable household income ranged between 0.22985 and 0.42985 , and the simulated results are shown in Figure 11.

The data are simulated 200 times. The coefficient of disposable household income in the 200 simulations is the average deviation in the range [0.22985, 0.42985], and 200 results of rigid demand increase for housing are obtained. Based on Figure 11, the blue curves in the center of the band chart represent the rigid demand increase for housing when the coefficient of disposable household income is 0.32985 . For different coefficients of disposable household income, $50 \%$ of rigid demand increases for housing fall in the region between the two yellow belts (i.e., 100 lines in the yellow region) and $75 \%$ fall in the region between the two green belts (i.e., 150 lines). After subtracting 100 lines in the yellow region, 50 lines remain in the green region. A total of $95 \%$ of rigid demand increases fall in the region between the two blue belts (i.e., 190 lines). After subtracting 150 lines, 40 lines remain in the blue region. A total of $100 \%$ of rigid demand increases fall in the region between the two gray belts (i.e., 200 lines). After subtracting 190 lines, 10 lines remain in the gray region.

According to the distribution patterns in the band chart of Figure 3, the coefficient of disposable household income has a small impact on rigid demand increase for housing when it fluctuates. Hence, it is reasonable to set a value for the coefficient of disposable household income, as it does not affect the model prediction trend.

\section{Results and Discussion}

4.1. Result Analysis. Inspection of the commodity housing price system dynamics model in the previous section reveals that the model is robust, which permits the prediction results to be analyzed.

Since 2003, the price of commercial residential buildings in Wuhan has continually increased (Figure 12). The increment was slow from 2011 to 2015, and the degree of increase continued to increase until 2021. After 2021, the growth in commercial housing prices flattens and is expected to reach $1,8207.9$ yuan $/ \mathrm{m}^{2}$ by 2030 [21].

4.2. Policy Regulation. The model simulation shows that the house price in Wuhan is expected to increase in the future. The effectiveness of the proposed policy can be observed through the policy regulation experiment, and the model can 


\begin{tabular}{|c|c|c|c|c|c|c|}
\hline Autocorrelation & \multicolumn{2}{|c|}{ Partial correlation } & AC & PAC & Q-Sta... & Prob \\
\hline I & 1 & 1 & $1-0.01 \ldots$ & $-0.01 \ldots$ & 0.0016 & 0.968 \\
\hline I & 1 & 1 & 20.256 & 0.256 & 1.2223 & 0.543 \\
\hline । & I & 1 & 30.100 & 0.111 & 1.4244 & 0.700 \\
\hline । & 1 & 1 & 40.097 & 0.039 & 1.6346 & 0.803 \\
\hline I & 1 & 1 & $5-0.27 \ldots$ & $-0.35 .$. & 3.5001 & 0.623 \\
\hline I & 1 & 1 & $6-0.03 \ldots$ & $-0.12 \ldots$ & 3.5359 & 0.739 \\
\hline I & 1 & 1 & $7-0.15 \ldots$ & $-0.01 \ldots$ & 4.2714 & 0.748 \\
\hline । & I & I & $8-0.33 \ldots$ & $-0.26 \ldots$ & 8.3288 & 0.402 \\
\hline । & 1 & 1 & $9-0.05 \ldots$ & 0.038 & 8.4456 & 0.490 \\
\hline । & 1 & 1 & $1 \ldots-0.04 \ldots$ & 0.068 & 8.5827 & 0.572 \\
\hline । & 1 & 1 & $1 \ldots-0.00 \ldots$ & 0.078 & 8.5882 & 0.660 \\
\hline । & 1 & 1 & $1 \ldots-0.04 \ldots$ & $-0.06 \ldots$ & 8.8302 & 0.717 \\
\hline
\end{tabular}

FIGURE 10: Autocorrelation and partial correlation diagram of first-order difference series of residential expected sales area.

TABLE 7: Estimated results of ARIMA model for expected residential sales area.

\begin{tabular}{lccc}
\hline Variable & Coefficient & Std. error & $t$-Statistic \\
\hline C & 183.8343 & 57.95232 & 3.172164 \\
R-squared & 0 & Mean dependent var & 0.0074 \\
Adjusted R-squared & 0 & SD dependent var & 183.8343 \\
SE of regression & 216.8377 & Akaike info criterion & 216.8377 \\
Sum squared resid & 611241.9 & Schwarz criterion & 13.66492 \\
Log likelihood & -94.65447 & Hannan-Quinn criterion & 13.71057 \\
Durbin-Watson stat & 2.007024 & & 13.6607 \\
\hline
\end{tabular}

TABLE 8: Autocorrelation test results of residual sequence.

\begin{tabular}{lccc}
\hline \multicolumn{4}{c}{ Breusch-Godfrey serial correlation LM test } \\
\hline F-statistic & 0.486671 & Prob. F (2,11) & 0.6273 \\
Obs R-squared & 1.138093 & Prob. Chi-Square (2) & 0.5661 \\
\hline
\end{tabular}

TABLE 9: Heteroscedasticity test results of residual sequence.

\begin{tabular}{lccc}
\hline \multicolumn{4}{c}{ Heteroskedasticity test: ARCH } \\
\hline F-statistic & 0.127598 & Prob. F (1,11) & 0.7277 \\
Obs R-squared & 0.149068 & Prob. Chi-Square (1) & 0.6994 \\
\hline
\end{tabular}

provide theoretical decision-making guidance for the government to regulate housing prices. The regulatory experiment is performed with respect to three aspects: developer loan interest rate, real estate tax rate, and purchase restriction.

(1) Policies of Regulating Loan Interest Rates for Developers. Regulatory policy 1 of developers' loan interest rate: The influence of regulatory policy for developer loan interest rate changed from 1 to $1+\operatorname{STEP}(0.2,2018)$, meaning that original policies were maintained before 2018. Since 2018, the policy influence level has increased by 0.2 . According to the previous relation equation of developer loan interest rate, the developer loan interest rate has increased by $20 \%$ since 2018 (from $5.43 \%$ in 2017 to $6.52 \%$ ).
Regulatory policy 2 of developers' loan interest rate: The influence of regulatory policy for developer loan interest rate changed from 1 to 1 -STEP $(0.2,2018)$, meaning that original policies were maintained before 2018. Since 2018, the policy influence level decreased by 0.2 . According to the previous relation equation of developers' loan interest rate, essentially, the developers' loan interest rate has decreased by $20 \%$ since 2018 (from $5.43 \%$ in 2017 to $4.34 \%$ ).

The experimental results on the regulation and control of developer loan interest rate policy using Vensim DSS software are as follows.

According to the above simulation results, if developer loan interest rate is low, the commercial housing price is low as well. If developer loan interest rate declines by $20 \%$, the commercial housing price also decreases by a maximum of $1.42 \%$ (Figure 13, Table 12).

According to the flow chart of the system dynamics model, if developer loan interest rate increases, comprehensive residence cost also increases, thus increasing the housing price. The massive amount of capital for developers to construct commercial residential buildings mainly stems from bank loans. Hence, if loan interest rate increases, the cost of capital for companies and construction also increases. The primary goal of residential development companies is to gain profits. To gain more profits, developers may transfer the increased cost to house purchasers. Consequently, commercial housing prices continually increase. From the perspective of house purchasers, loan interest rise also increases the cost of purchasing houses. With the fixed amount 
TABLE 10: Forecast value of expected residential sales area in Wuhan.

\begin{tabular}{|c|c|c|c|c|c|c|c|}
\hline Year & 2018 & 2019 & 2020 & 2021 & 2022 & 2023 & 2024 \\
\hline Expected residential sales area & 3269.61 & 3453.45 & 3637.28 & 3821.12 & 4004.95 & 4188.79 & \\
\hline Year & 2025 & 2026 & 2027 & 2028 & 2029 & 2030 & 4372.62 \\
\hline Expected residential sales area & 4556.45 & 4740.29 & 4924.12 & 5107.96 & 5291.79 & 5475.63 & \\
\hline
\end{tabular}

According to the above simulation, the table function of the expected residential sales area can be obtained.

TABLE 11: Comparison between simulation and actual data.

\begin{tabular}{cccc}
\hline & \multicolumn{3}{c}{$\begin{array}{c}\text { Inspection of historical data of housing price } \\
\text { Simulation value (ten thousand people) }\end{array}$} \\
\hline 2003 & True value (ten thousand people) & 2023 & 0 \\
2004 & 2023.00 & 2499.38 & 1.49 \\
2005 & 2462.73 & 3074.79 & 2.97 \\
2006 & 2986.20 & 3531.32 & -1.18 \\
2007 & 3535.26 & 4467.98 & -1.06 \\
2008 & 4515.76 & 4533.65 & -3.15 \\
2009 & 4681.00 & 4928.45 & -5.20 \\
2010 & 5199.00 & 5663.21 & 2.04 \\
2011 & 5550.00 & 6565.13 & -1.66 \\
2012 & 6675.99 & 6561.01 & -4.85 \\
2013 & 6895.35 & 7084.88 & -2.12 \\
2014 & 7238.00 & 7225.17 & -2.35 \\
2015 & 7399.00 & 7890.65 & -6.11 \\
2016 & 8404.00 & 9475.54 & -3.50 \\
2017 & 9819.00 & 10411.2 & -9.09 \\
\hline
\end{tabular}

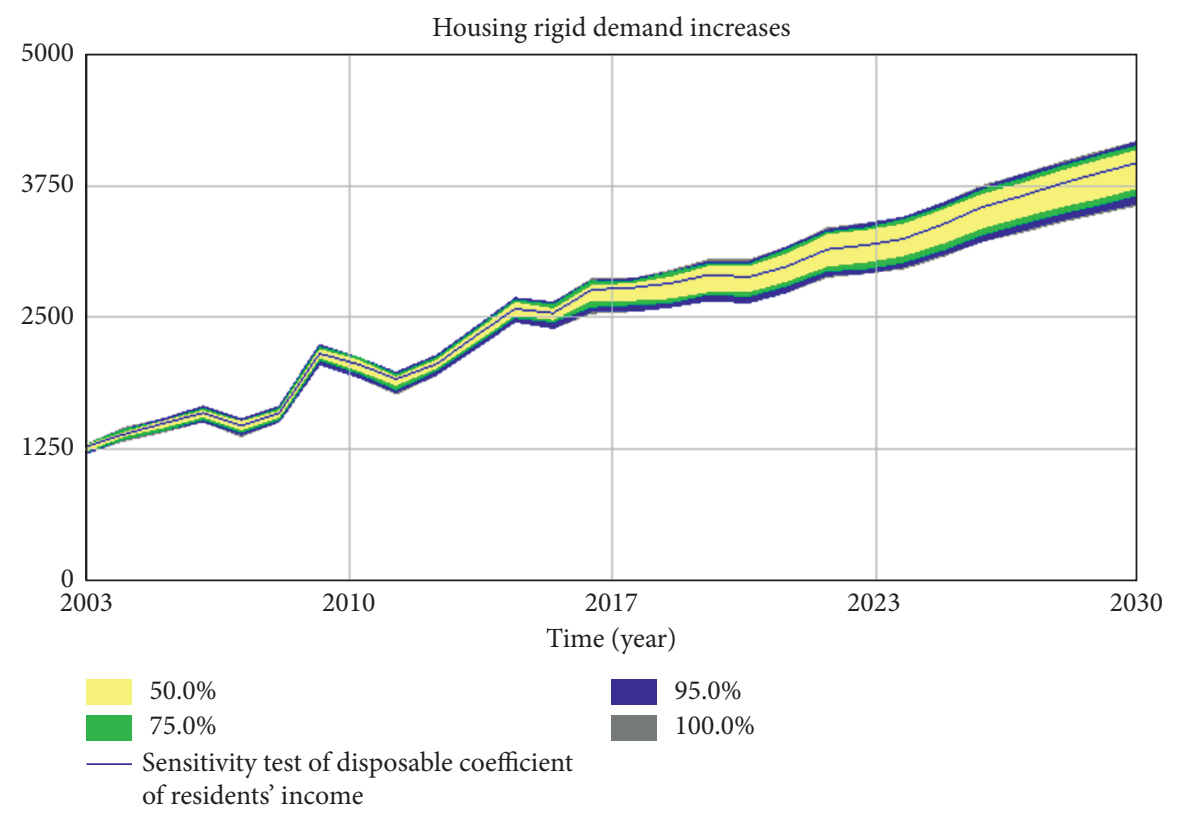

FIgURE 11: Sensibility test of the coefficient of disposable household income on rigid demand increase. 


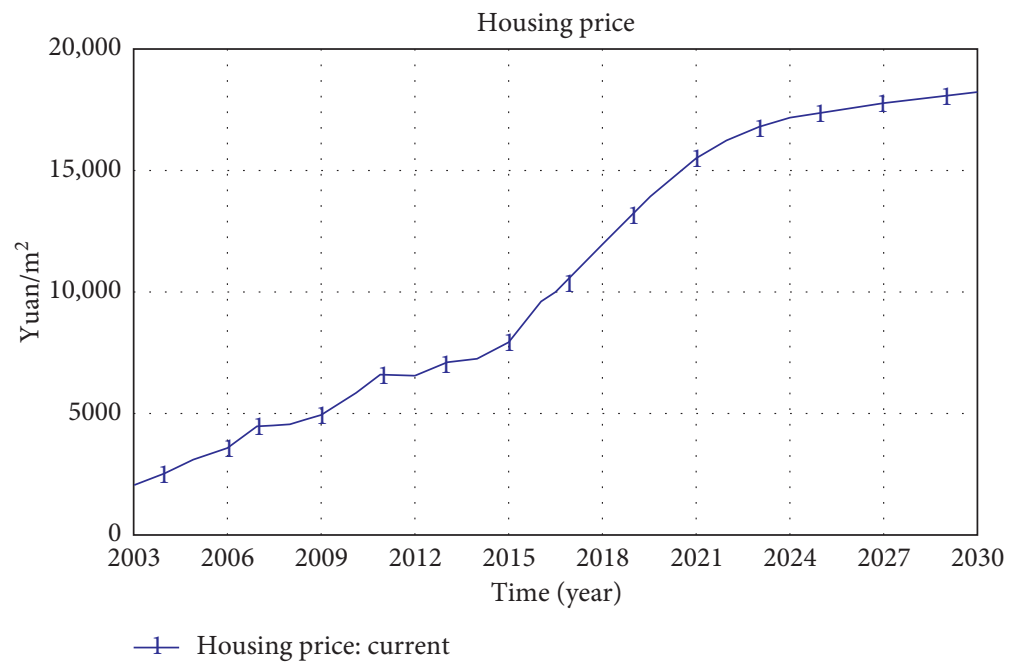

FIGURE 12: Forecast value of commodity housing price. (reproduced from J. Y. Guo and J. W. Wang's article[21]: "Housing price research based on system dynamics model," IOP Conference Series: Earth and Environmental Science, ISTTCA, 2020).

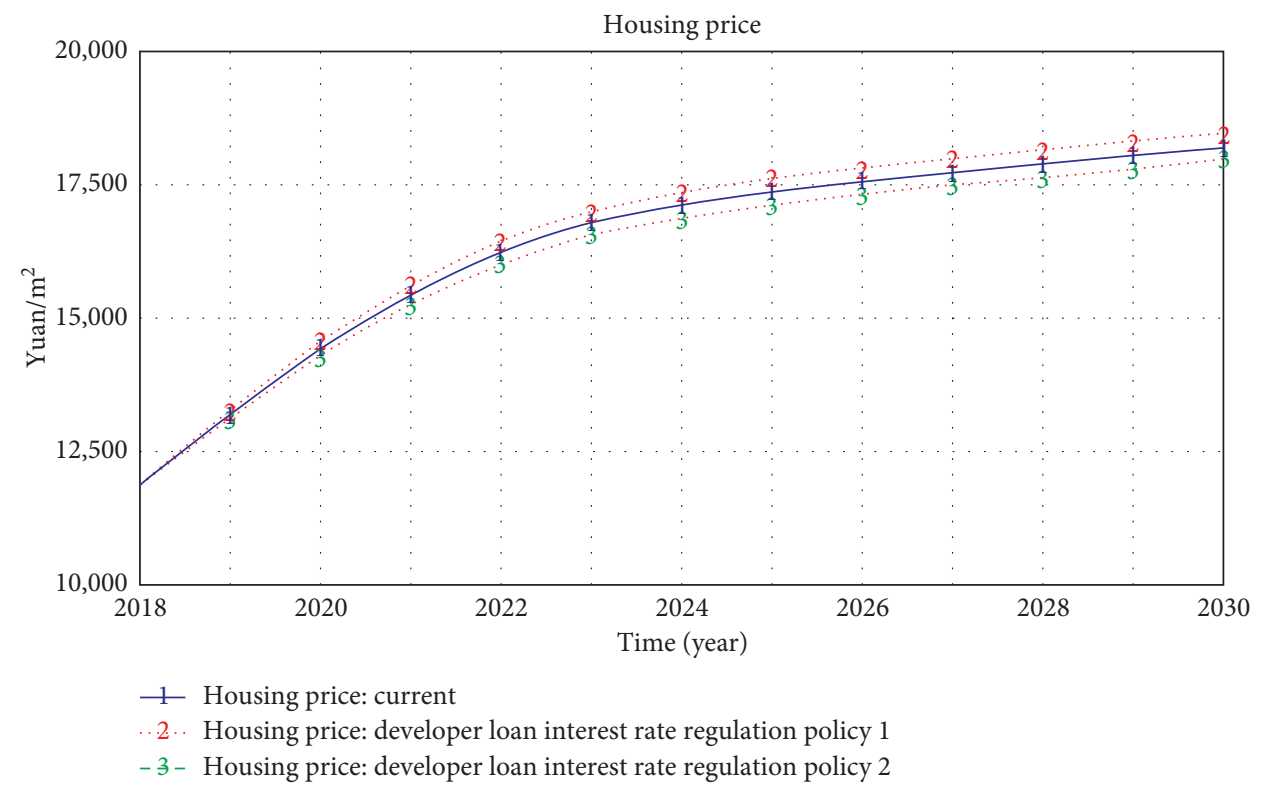

FIGURE 13: Influence of developer loan interest rate policy regulation on housing price.

TABLE 12: Comparison table of housing prices under the regulation of developer loan interest rate policy.

\section{Housing price}

Year Primitive regulation Regulatory policy 1 of developers' loan interest rate Regulatory policy 2 of developers' loan interest rate Original value $\left(\right.$ Yuan $\left./ \mathrm{m}^{2}\right)$ Regulation value $1\left(\right.$ Yuan $\left./ \mathrm{m}^{2}\right)$ Rate of change (\%) Regulation value $2\left(Y u a n / \mathrm{m}^{2}\right) \quad$ Rate of change $(\%)$

\begin{tabular}{lccccc}
\hline 2018 & 11861 & 11861 & 0 & 11861 & 0 \\
2019 & 13172.2 & 13226.8 & 0.415 & 13117.6 & -0.415 \\
2020 & 14403.4 & 14534.1 & 0.907 & 14272.3 & -0.910 \\
2021 & 15433.4 & 15618.6 & 1.200 & 15248 & -1.201 \\
2022 & 16233.6 & 16450.5 & 1.336 & 16016.5 & -1.337 \\
2023 & 16768.6 & 17002.1 & 1.392 & 16534.9 & -1.393 \\
2024 & 17113.4 & 17355.5 & 1.415 & 16871.1 & -1.416 \\
2025 & 17355.2 & 17602.1 & 1.423 & 17108.2 & -1.423 \\
2026 & 17548.4 & 17798.3 & 1.424 & 17298.3 & -1.425 \\
2027 & 17721 & 17973.2 & 1.423 & 17468.6 & -1.424 \\
2028 & 17885.5 & 18139.7 & 1.421 & 17631.1 & -1.422 \\
2029 & 18046.9 & 18303 & 1.419 & 17790.7 & -1.420 \\
2030 & 18207.9 & 18465.8 & 1.416 & 17949.8 & -1.418 \\
\hline
\end{tabular}




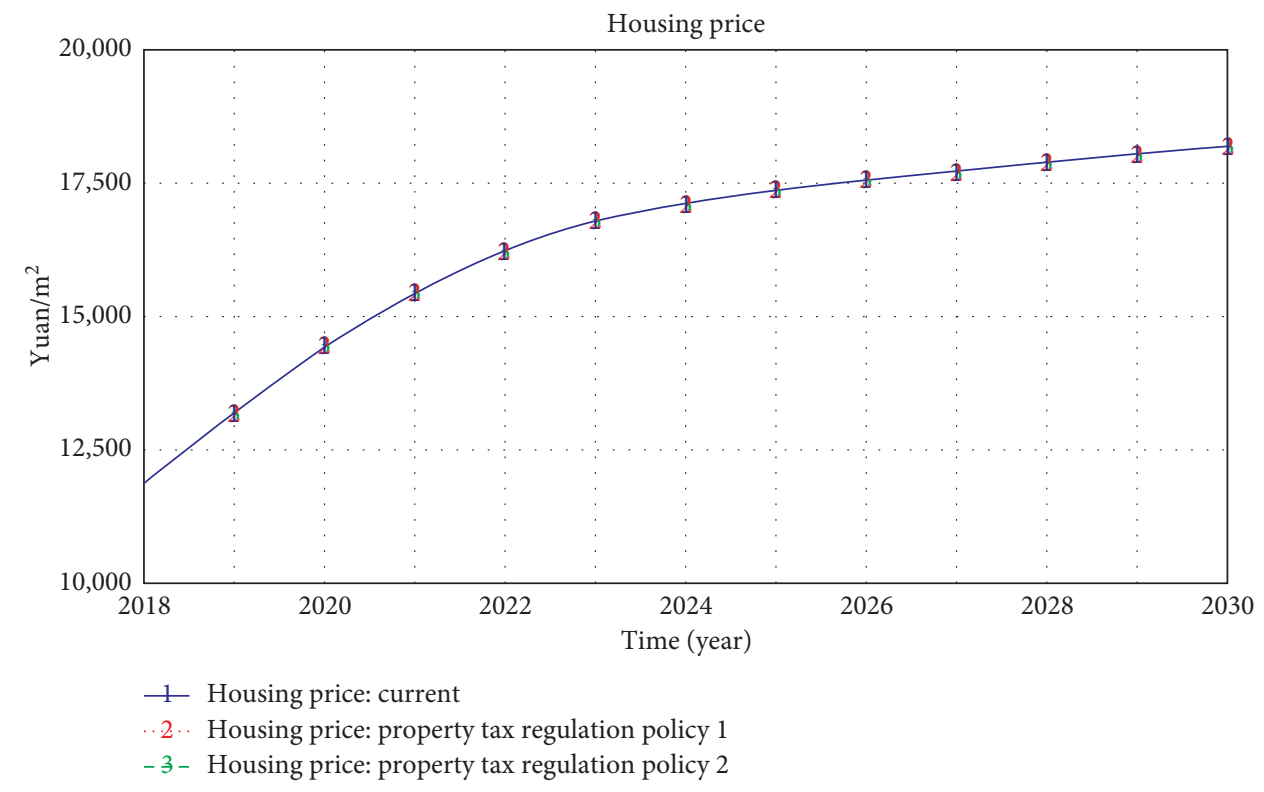

FIGURE 14: Influence of property tax policy regulation on housing price.

TABLE 13: Comparison table of housing prices under the regulation of property tax policy.

\begin{tabular}{|c|c|c|c|c|c|}
\hline \multirow{3}{*}{ Year } & \multicolumn{5}{|c|}{ Housing price } \\
\hline & \multirow{2}{*}{$\begin{array}{c}\text { Primitive regulation } \\
\text { Original value (Yuan } / \mathrm{m}^{2} \text { ) }\end{array}$} & \multicolumn{2}{|c|}{ Regulatory policy 1 of property tax } & \multicolumn{2}{|c|}{ Regulatory policy 2 of property tax } \\
\hline & & Regulation value 1 (Yuan $\left./ \mathrm{m}^{2}\right)$ & Rate of change (\%) & Regulation value 2 (Yuan $/ \mathrm{m}^{2}$ ) & Rate of change (\%) \\
\hline 2018 & 11861 & 11861 & 0 & 11861 & 0 \\
\hline 2019 & 13172.2 & 13172.1 & -0.001 & 13171.6 & -0.005 \\
\hline 2020 & 14403.4 & 14403.2 & -0.001 & 14401.6 & -0.012 \\
\hline 2021 & 15433.4 & 15433 & -0.003 & 15429.9 & -0.023 \\
\hline 2022 & 16233.6 & 16233.1 & -0.003 & 16228.5 & -0.031 \\
\hline 2023 & 16768.6 & 16767.9 & -0.004 & 16762.2 & -0.038 \\
\hline 2024 & 17113.4 & 17112.7 & -0.004 & 17106.2 & -0.042 \\
\hline 2025 & 17355.2 & 17354.4 & -0.005 & 17347.4 & -0.045 \\
\hline 2026 & 17548.4 & 17547.5 & -0.005 & 17540 & -0.048 \\
\hline 2027 & 17721 & 17720.1 & -0.005 & 17712.2 & -0.050 \\
\hline 2028 & 17885.5 & 17884.5 & -0.006 & 17876.1 & -0.053 \\
\hline 2029 & 18046.9 & 18045.9 & -0.006 & 18037.1 & -0.054 \\
\hline 2030 & 18207.9 & 18206.9 & -0.005 & 18197.7 & -0.056 \\
\hline
\end{tabular}

of disposable income, cost increase places more pressure on the payment of house purchasers and thus reduces their willingness to purchase. With a constant supply, the total demand for housing decreases, resulting in a decline in commercial housing prices. Thus, interest rate adjustment has a minor effect on commercial housing prices.

(2) Policy Regulation of Property Tax Rate. As Wuhan has not yet collected property tax, the property tax rate in the previous simulation forecast is 0 . This regulation test is as follows:

Regulatory policy 1 of property tax: assume that a property tax of $1 \%$ should be paid since 2018 .

Regulatory policy 2 of property tax: assume that a property tax of $5 \%$ should be paid since 2018 .
The experimental results of property tax rate policy regulation by Vensim DSS software are as follows.

According to the above simulation results, if the property tax rate increases, commercial housing price declines. If the tax rate of purchasing the second house increases by $20 \%$, the commercial housing price declines by a maximum of $0.06 \%$, resulting in a relatively minor amplitude of variation (Figure 14, Table 13).

According to the flow chart of the system dynamics model, increases in property tax lead to decreases in the investment demand for housing, thereby decreasing the overall demand for housing. With a fixed level of supply, the rise in the supply-demand ratio can lead to a reduction in housing prices. The property tax policies in Shanghai and Chongqing are mainly targeted at investment housing, which does not account for a significant ratio of the overall 


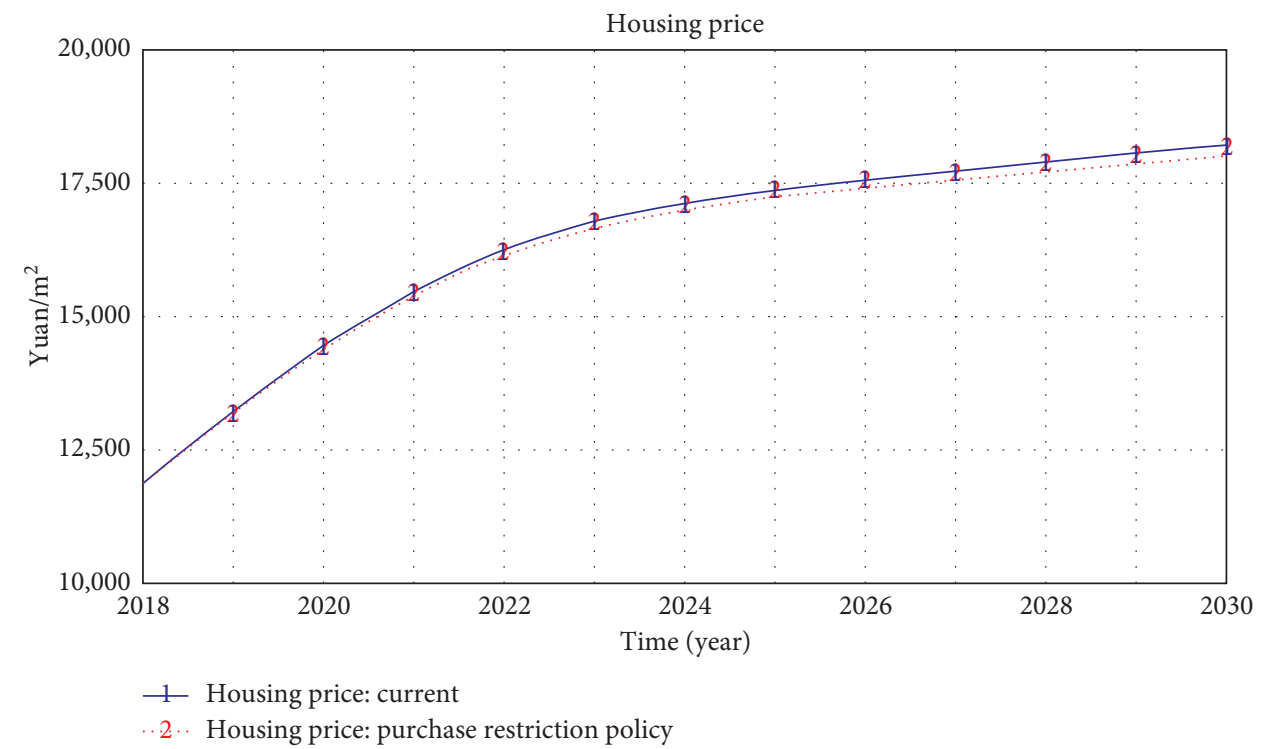

FIGURE 15: Influence of the regulation of purchase restriction policy on housing prices.

TABLE 14: Comparison table of housing prices under the control of purchase restriction policy.

\begin{tabular}{lccc}
\hline & & Housing price & \\
Year & $\begin{array}{c}\text { Restriction control policy } \\
\text { Orimitive regulation }\end{array}$ & \multicolumn{2}{c}{ Rate of change $(\%)$} \\
\hline 2018 & 11861 & 11861 & 0 \\
2019 & 13172.2 & 13161.8 & -0.079 \\
2020 & 14403.4 & 14367.2 & -0.251 \\
2021 & 15433.4 & 15365.3 & -0.441 \\
2022 & 16233.6 & 16134.6 & -0.610 \\
2023 & 16768.6 & 16646.1 & -0.731 \\
2024 & 17113.4 & 16974.4 & -0.812 \\
2025 & 17355.2 & 17204.1 & -0.871 \\
2026 & 17548.4 & 17387.1 & -0.919 \\
2027 & 17721 & 17550.4 & -0.963 \\
2028 & 17885.5 & 17705.7 & -1.005 \\
2029 & 18046.9 & 17858 & -1.047 \\
2030 & 18207.9 & 18009.9 & -1.087 \\
\hline
\end{tabular}

demand for housing. In addition, the property tax rate is relatively low and thus has a minor influence on commercial housing prices.

(3) Purchase Restriction Policy Regulation. The purchase restriction simulation experiment considers the extreme case: assuming that second house purchasing is restricted and thus only purchasing one house is feasible. In this case, there is no demand for investment housing.

Experimental results on the regulation and control of purchase restriction policy using Vensim DSS software are as follows.

After the implementation of the purchase restriction policy in the above simulation, commercial housing prices decline by a maximum of $1.08 \%$, and the range of variation is low (Figure 15, Table 14). The purchase restriction policy is mainly targeted at those not purchasing houses for the first time.

\section{Conclusion}

The main factors affecting the price of commercial housing in Wuhan were determined in this paper, and the relationship equations between these factors were constructed. The system dynamics model of house price was successfully established; it simulates the housing market operation in Wuhan over time and predicts the price of commercial housing in Wuhan over the next few years. From the perspective of the developer loan interest rate, real estate tax rate, purchase restriction, and other policies, we showed that the developer loan interest rate regulation policy is more effective for guiding changes in commercial housing prices. Commercial housing was the focus of this research; consequently, other real estate types, such as shops, were not considered. Future research should more comprehensively consider various types of real estate and provide 
countermeasures for the regulation and control of the entire property market.

\section{Data Availability}

The case analysis data used to support the findings of this study are available from the corresponding author upon request.

\section{Conflicts of Interest}

The authors declare that there are no conflicts of interest regarding the publication of this paper.

\section{References}

[1] Y. T. Liu and Z. Zhen, "Analysis and forecast of Lanzhou commercial house price change based on MATLAB," Journal of Gansu Sciences, vol. 23, no. 3, pp. 155-158, 2011.

[2] X. L. Lian, "Comparison of forecasting models of house price index in China," Price Theory and Practice, no. 7, pp. 42-43, 2010.

[3] B. N. Zhu, "Research on influencing factors and prediction of commercial house price based on grey prediction," Time Finance, no. 12, pp. 275-277, 2017.

[4] X. J. Zhou and W. X. Chen, "House price forecast of Huanggang city based on BP algorithm of artificial neural network," Journal of Huanggang Normal University, vol. 34, no. 1, pp. 13-15, 2014

[5] P. H. Hendershott and M. Charlotte, "An anatomy of price dynamics in illiquid markets: analysis and evidence from local housing markets," Real Estate Economics, vol. 32, no. 1, pp. 1-32, 2004.

[6] E. Balazs and D. Mihaljek, "Determinants of house prices in central and eastern europe," Comparitive Economic Studies, William Davidson Institute Working Paper, vol. 49, , pp. 89-94, 2007.

[7] S. Hwang, M. Park, and H. S. Lee, "Dynamic analysis of the effects of mortgage-lending policies in a real estate market," Mathematical and Computer Modeling, vol. 57, no. 9, pp. 2106-2120, 2013.

[8] X. J. Ji, Simulation of Nanjing Commodity Housing price System Dynamics Model, Nanjing University of Aeronautics and Astronautics, Nanjing, China, 2008.

[9] R. X. Wang and W. L. Wang, "System simulation and prediction of housing market based on system dynamics-taking Xi' an as an example," Journal of Ankang University, vol. 23, no. 3, pp. 37-42, 2011.

[10] G. P. Tu and Z. J. Huang, "Simulation study on demand of commercial housing based on system dynamics-taking Nanchang as an example," Journal of East China University of Science and Technology, no. 6, pp. 62-68, 2012.

[11] Y. H. Chen and Z. Z. Liao, "Price analysis of commercial housing in Wuhan based on system dynamics," Science Technology and Engineering, vol. 12, no. 33, pp. 9132-9136, 2012.

[12] Y. Z. Chen, "Analysis of factors influencing Xiangtan real estate housing price based on SD model," Science and Technology Plaza, no. 5, pp. 205-209, 2012.

[13] Y. Shen and X. T. Ma, "Research on simulation of housing price change based on system dynamics-empirical evidence from Shanghai," Journal of Dalian University of Technolgy, vol. 34, no. 2, 2013.
[14] Y. T. Ma, System Dynamics Simulation Research on Regulation Policy of Commercial Housing Market in Hangzhou, Zhejiang University, Hangzhou, China, 2014.

[15] L. Hu, S. He, Z. Han et al., "Monitoring housing rental prices based on social media:an integrated approach of machinelearning algorithms and hedonic modeling to inform equitable housing policies," Land Use Policy, vol. 82, pp. 657-673, 2019.

[16] H. Zhang, Socialization-oriented Centralized Youth LongTerm Rental Apartment Design, Southeast University, Nanjing, China, 2019.

[17] Wang, System dynamics, Shanghai University of Finance and Economics Press, Shanghai, China, 2009.

[18] H. Oh, H.-C. Kim, K. W. Hong, and S. He, "A dynamic perspective of meeting planners satisfaction: toward conceptualization of critical relevancy," Tourism Management, vol. 30, no. 4, pp. 471-482, 2009.

[19] E. Hjalmarsson and P. Österholm, “"Heterogeneity in households' expectations of housing prices - evidence from micro data," Journal of Housing Economics, vol. 50, 2020.

[20] Gao, Econometric Analysis Method and Modeling reviews Application and Example, Tsinghua University Press, Beijing, China, 2016.

[21] J. Y. Guo and J. W. Wang, Housing price research based on system dynamics model, in Proceedings of the IOP Conference Series: Earth and Environmental Science, ISTTCA, Changchun, China, Augest 2020.

[22] Wang, Research on Influencing Factors and Driving Policies of Industrial Internet Platform Development in China, Beijing University of Civil Engineering and Architecture, Beijing, China, 2020. 